HISPANIA. Revista Española de Historia, 2009, vol. LXIX, núm. 233, septiembre-diciembre, págs. 619-652, ISSN: 0018-2141

\title{
ARQUEOLOGÍA de lOS ESPACIOS AGRARIOS MEDIEVALES EN EL PAÍS VASCO
}

\section{JuAn ANTONio Quirós CASTILlO ${ }^{1}$}

Universidad del País Vasco

RESUMEN: El objetivo de este trabajo es el de analizar, a la luz de los trabajos arqueológicos realizados en los últimos años, las transformaciones de la sociedad rural medieval en el País Vasco. Para ello se presentan y se analizan tres tipos de testimonios arqueológicos principales: los espacios de cultivo (procesos de abonado, espacios aterrazados); las estructuras de almacenaje y las especies cultivadas. A partir de estos registros se realiza una caracterización diacrónica de los paisajes rurales vascos, poniendo el acento sobre el territorio alavés durante los siglos V-XII. Las prácticas agrarias documentadas permiten sostener la existencia de un paisaje bien estructurado en la Alta Edad Media, transformado en el siglo VIII mediante la creación de densas redes de aldeas. Con el cambio de milenio se realizan silos de renta y se produce una reorientación de las actividades productivas en el marco de una lógica social de carácter feudal.

Palabras clave: Terraza. Edad Media. Arqueología Agraria. Álava. País Vasco.

\section{THE ARCHAEOLOGY OF MEDIEVAL AGRARIAN SPACES IN THE BASQUE COUNTRY}

ABSTRACT: The objective of this paper is to analyze the changes undergone by medieval rural societies in the Basque Country on the basis of archaeological digs undertaken in the last few years. Three types of archaeological evidence are presented and discussed: the cultivation spaces (manuring processes, terraced spaces), the storage

Juan Antonio Quirós Castillo es profesor en la Universidad del País Vasco. Dirección para correspon-dencia: Dpto. Geografía, Prehistoria y Arqueología, C/ F. Tomás y Valiente, s/n, 01006, Vitoria-Gasteiz.E-mail: quiros.castillo@ebu.es

1 Grupo de Investigación en Arqueología Medieval y Postmedieval. Área de Arqueología. Universidad del País Vasco, C/ F. Tomás y Valiente s/n, 01006, Vitoria-Gasteiz, quiros.castillo@ehu.es. Trabajo realizado en el marco del proyecto de investigación HUM2009-07079 financiado por el Ministerio de Educación y Ciencia en el ámbito del Plan Nacional de I+D+I titulado «La formación de los paisajes medievales en el Norte Peninsular y en Europa: Agricultura y ganadería los siglos V al XII». 
structures and the species cultivated. These findings allow a diachronic characterization of Basque rural landscapes, with emphasis on the region of Alava during the 5th-12th centuries. The agrarian techniques documented allow us to propose the existence of a well-structured landscape in the Early Middle Ages, which changed in the 8th century due to the creation of dense village networks. Income silos which resulted in a reorientation of production activities in the framework of a feudal-type social system, are found towards the end of the millennium.

KeY WORDS: Terrace. Middle Ages. Agrarian Archaeology. Alava. Basque Country.

\section{INTRODUCCIÓN}

El estudio de los espacios agrarios medievales del País Vasco cuenta con una tradición de estudios que se remonta a los años 70, cuando J.A. García de Cortazar comenzó a estudiar problemas como la «organización del territorio» y la «sociedad alavesa» a partir de su innovador trabajo sobre el cartulario de San Millán de la Cogolla realizado unos años antes. En dos trabajos fechados en los años 1981 y 1982 se pusieron las bases de los paradigmas que, hasta hace no muchos años, han condicionado la historia social y económica del País Vasco del período medieval antes de la fundación de las villas bajomedievales. En estos trabajos se planteaba como a partir de siglo IX se habría producido una «aculturación» que habría comportado, entre otros efectos, una modificación de las dedicaciones económicas tradicionales basadas en la ganadería y la introducción de una nueva organización del espacio que conduciría a la implantación del feudalismo².

Discípulos suyos, como por ejemplo R. Díaz de Durana en el caso alavés, han trazado a partir de los testimonios escritos síntesis territoriales en los que también se han analizado de forma más o menos directa la organización de los espacios agrarios. En este trabajo se prestó una atención especial al fenómeno de la crisis y las transformaciones que tuvieron lugar en Álava a partir de un estudio muy sistemático de las fuentes relacionadas con las producciones agra-

2 García de Cortazar, J.A., El dominio del monasterio de San Millán de la Cogolla (siglos XXIII)... Introducción a la historia rural de la Castilla altomedieval, Salamanca, Universidad de Salamanca, 1969; GARCÍA DE CORTAZAR, J.A., «La organización del territorio en la formación de Álava y Vizcaya en los siglos VIII a fines del XI», en: El hábitat en la historia de Euskadi, Bilbao, Colegio de Arquitectos Vasco-Navarro, 1981, págs. 133-155; GARCíA DE CORTAZAR, J.A., «La sociedad alavesa medieval antes de la concesión del fuero de Vitoria», en: Vitoria en la Edad Media, Vitoria, Ayuntamiento de Vitoria, 1982, págs. 89-114. Una valoración historiográfica a escala más amplia se puede consultar en García De Cortazar, J.A., MARTínez SopenA, P., "Los estudios sobre historia rural de la sociedad medieval hispanocristiana», en: AlfONSO, I., La Historia rural de las sociedades medievales europeas, Valencia, Universitat de València, 2008, págs. 97-143. 
rias. Pero no se realizó un análisis de detalle sobre la organización de los espacios productivos ${ }^{3}$.

En los últimos años sí se han producido modificaciones y transformaciones importantes en los planteamientos teóricos y metodológicos a partir de la introducción de nuevas orientaciones y planteamientos. Debemos a Ernesto Pastor $^{4}$, que sigue de cerca algunas de las conclusiones alcanzadas por J.J. Larrea en el cercano territorio navarro y sus propios estudios realizados en Castilla ${ }^{5}$, la introducción en nuestro territorio del concepto del crecimiento agrario altomedieval como punto de partida a partir del cual se produce la formación del feudalismo. Buena parte de la argumentación utilizada, como plantearé más adelante, se basa más en los silencios documentales altomedievales y en las «revelaciones» que aparecen en los textos fechables tras el año mil que en sólidas argumentaciones contrastables ${ }^{6}$. Y aunque se trata de una hipótesis muy sugerente, aún no se puede aceptar tal y como ha sido formulada.

Esta renovación historiográfica coincide con la elaboración de las primeras síntesis de un cierto calado realizadas a partir de los restos materiales sobre la historia medieval del País Vasco. Merece la pena señalar a este propósito el importante trabajo de Iñaki García Camino, que ha logrado sistematizar para buena parte del territorio vizcaíno un registro arqueológico bastante disperso y a la vez complejo, con el fin de trazar una primera síntesis territorial en la que se integran tanto los testimonios escritos como los restos materiales. Precisamente en este trabajo se realiza el primer estudio arqueológico de un espacio agrario, más concretamente en el caso del parcelario de Momoitio ${ }^{7}$. En este lugar se excavó una iglesia con un pequeño cementerio construido hacia el año 800 que perduró aproximadamente hasta el 1100. La iglesia, en cambio, ha pervivido hasta la actualidad aunque ha sido transformada en varias ocasiones. Aunque no se localizaron las estructuras domésticas de la aldea asociada al templo, el análisis morfológico del parcelario dio pie para sugerir la existencia de unidades domésticas próximas a la iglesia debido a la homogeneidad de las parcelas. Por otro lado la excavación de algunas de las campas y las parcelas situadas en su proximidad permitieron verificar, al menos en dos ocasiones, la existencia de terrazas artificiales en la que se identificaron cerámicas de crono-

3 Díaz de Durana, J.R., Álava en la Baja Edad Media. Crisis, recuperación y transformaciones socioeconómicas (c. 1250-1525), Vitoria, Diputación Foral de Álava, 1986.

4 PASTOR Díaz De GARAYO, E., «Las transformaciones de los siglos XI y XII. La instauración del feudalismo (la feudalización)», en: De la Romanización a la conquista de Navarra (siglos I-XVI). Historia de Euskalherria. Historia General de los Vascos, Tomo 2, Bilbao, Lur, 2006, págs. 182-247, pág. 213.

5 Larrea, J.J., La Navarre du IVe au XIIe siècle. Peuplement et sociètè, 1998.

6 ALFONSO, I., «¿Continuidad y revelación documental o mutación y revolución feudal?», Hispania, 55 (1995), págs. 301-313.

7 García Camino, I., Arqueología y poblamiento en Bizkaia, siglos VI-XII. La configuración de la sociedad feudal, Bilbao, Diputación Foral de Bizkaia, 2002, págs. 273-274. 
logía medieval ${ }^{8}$ (zona 1 y zona 5). En términos interpretativos, tras haber analizado numerosas evidencias arqueológicas, este autor se suma al paradigma del crecimiento económico que debió desarrollarse «desde finales del siglo VIII, pero sobre todo en los siglos IX y X»", asumiendo de esta manera los planteamientos explícitamente formulados desde la escuela historiográfica antes señalada, y en la que la existencia de un crecimiento agrario en la Alta Edad Media constituye un motor de cambio histórico de gran capacidad explicativa ${ }^{10}$.

Curiosamente, otros trabajos doctorales realizados recientemente en el País Vasco en torno a temáticas tan distintas como la producción de la cerámica o la arquitectura eclesiástica vuelven a abrazar estos planteamientos interpretativos, creemos que basándose más en los silencios que igualmente parece presentar el registro arqueológico de los siglos VI y VII, que en la existencia de sólidos elementos que permitan pensar en transformaciones significativas de las prácticas agrarias en el País Vasco durante la Alta Edad Media ${ }^{11}$.

Desde nuestro punto de vista, la existencia o no de un crecimiento agrario altomedieval en el País Vasco, como en cualquier otro territorio, y el establecimiento de sus posibles implicaciones en términos históricos ha de ser un proceso a demostrar más que un apriorismo asumido de forma acrítica. En segundo lugar, su existencia precisa de una explicación, y sobre todo, de un sujeto social. Los especialistas de otras áreas que han abordado esta cuestión se dividen claramente en dos posiciones prácticamente contrapuestas: aquéllos que atribuyen un papel protagonista a la acción espontánea del propio campesinado durante la Alta Edad Media apoyándose en fenómenos como el crecimiento demográfico o la saturación demográfica llevando a cabo procesos de colonización o fundación de nuevos asentamientos sobre los que se basará la construcción de los poderes señoriales ${ }^{12}$; otros, en cambio, prefieren destacar el papel

8 García Camino, I., Arqueología y poblamiento ..., págs. 115-118, Lam. I.

9 García Camino, I., Arqueología y poblamiento..., pág. 377.

10 Ver igualmente García Camino, I., «La Alta Edad Media en el País Vasco. Siglos VIII-X», en: De la Romanización a la conquista de Navarra (siglos I-XVI). Historia de Euskalherria. Historia General de los Vascos, Tomo 2, Bilbao, Lur, 2006, págs. 116-180, págs. 146 y ss.

11 Solaun, J.L., La cerámica medieval en el País Vasco (siglos VIII-XIII), Sistematización, evolución $y$ distribución, Vitoria, Universidad del Pais Vasco, 2005, pág. 403; SÁnCHEZ ZuFiaurre, L., Técnicas constructivas altomedievales. Nuevos documentos arqueológicos para el estudio de la Alta Edad Media en Álava, Vitoria, Universidad del País Vasco, 2007, pág. 331. De hecho se asumen como apriorismos explicativos. A este propósito merece la pena recordar que se han formulado propuestas interpretativas alternativas que explicarían procesos como la multiplicación de las iglesias privadas a partir de un determinado período, o la estructuración de sistemas artesanales complejos a partir de los últimos siglos altomedievales sin necesidad de recurrir a un modelo de «crecimiento».

12 Por ejemplo Bonnassie, P., Cataluña mil años atrás (siglos X-XI), Barcelona, Crítica, 1988; SAlRach MAES, J.M., La formación del campesinado en el occidente antiguo y medieval. Análisis de los cambios en las condiciones de trabajo desde Roma clásica al feudalismo, Madrid, Síntesis, 1997, pág. 143. Desde otros planteamientos atribuyen igualmente un papel destacado a la acción espontánea del campesinado autores como FrANCOVICH, R., HODGES, R., Villa to village. The transformation of the Roman Countryside in Italy, c. 400-1000, London, Duckworth, 2003. 
protagonista de élites locales o poderes aristocráticos de vario tipo cuya presencia nunca habría cesado en el curso de la Alta Edad Media habiendo liderado un determinado crecimiento agrario o impulsado una reordenación de los espacios rurales ${ }^{13}$. Pero además de los sujetos, es preciso también concretizar en qué consiste este crecimiento. ¿Es de carácter cualitativo o de carácter cuantitativo? ¿supone únicamente un aumento de los espacios cultivados o un cambio de las especies cultivadas? ¿cómo se modifican las prácticas agrarias? ¿se produce un aumento de la ganadería extensiva, como han propuesto algunos autores, o bien de una ganadería estante vinculada a la agricultura? ${ }^{14}$. Otro aspecto de la definición de estos problemas consiste en validar y revisar hasta qué punto los siglos VI-VIII pueden seguir siendo caracterizados como un período dominado por la actividad ganadera (sin soportes documentales adecuados) y cómo se pasa a partir del siglo IX a una economía presidida por la agricultura ${ }^{15}$. Por último, y no menos importante, el «milenarismo» que ha dominado buena parte de la historiografía de los últimos decenios ha llevado a situar el siglo XI como un punto de llegada, integrando en un mismo proceso fenómenos que pueden (y de hecho así ha sido) haberse desarrollado durante siglos.

Teniendo en cuenta todas estas inquietudes, y sabiendo que nadamos contra corriente, se ha iniciado un proyecto de investigación sobre la configuración de los paisajes medievales en el País Vasco con el fin de comprender las transformaciones de las prácticas agrarias. Las bases conceptuales y las herramientas metodológicas que se han ido implementando para desarrollar este proyecto han ido variando a lo largo del tiempo. Si en un primer momento centramos nuestra atención en el denominado estudio del "poblamiento» a partir del estudio de los despoblados, hemos ido evolucionando hacia un estudio más integral de los paisajes, prestando una atención especial al análisis del campesinado.

\section{MARCos CONCEPTUALES DE LA ARQUEOLOGÍA AGRARIA}

Hace ya más de veinte años, en su importante trabajo sobre la Arqueología Medieval en las afueras del Medievalismo, M. Barceló planteaba cómo el espa-

13 Por ejemplo Rösener, W., I contadini nella storia d'Europa, Roma, Laterza, 1995, pág. 65; desde un planteamiento arqueológico, Brogiolo, G.P., Chavarria Arnau, A., Aristocrazie e campagne nell'Occidente da Costantino a Carlo Magno, Firenze, All'insegna del Giglio, 2005.

14 A escala europea ver HAMEROw, H., Early medieval settlements. The archaeology of rural communities in North-West Europe 400-900, Oxford, Oxford University Press, 2002, pág. 139 y ss. y FOWLER, P., Farming in the first millennium AD. British agriculture between Julius Caesar and William the Conqueror, Cambridge, Cambridge University Press, 2002.

15 Este paradigma preside muchas síntesis sobre la economía altomedieval, debido tanto a la abundante normativa conservada en las fuentes escritas relativa a la ganadería, como a la importancia otorgada por los análisis paleobotánicos recientes a los fenómenos de la quema y tala de bosques en altura para la creación de espacios de pasto. 
cio rural debía de ser analizado en toda su complejidad como resultado de la articulación de zonas de asentamiento y del conjunto de áreas en las que tienen lugar los procesos de trabajo necesarios para la reproducción social. Y aunque la Arqueología se había especializado en el estudio de las denominadas «áreas residenciales», era en los campos de cultivo, en los espacios de producción donde era necesario explicar las desigualdades sociales, objetivo último de cualquier investigación histórica de calidad ${ }^{16}$. A lo largo de los años este autor, como su equipo, ha profundizado en esta línea llegando a plantear que

«es la hora de la arqueología refundada, que tenga por objeto principal los campos de trabajo campesinos en todas sus dimensiones sociales para poder llegar a establecer el sentido y las cronologías de la erosión constante de su autonomía (...) La arqueología de las zonas de residencia, para esta cuestión, puede ofrecer a lo sumo imágenes imprecisas del paso de los productos por ellas, de su elaboración cuando ésta se hace en las casa o de su almacenamiento, además de precisar en algunos casos de qué productos se trata. Pero el resto sólo puede ser buscado en los mismos campos donde se desarrollaron los procesos de trabajo» ${ }^{17}$.

Estas poderosas herramientas conceptuales que nos han inspirado a generaciones de estudiosos que pretendíamos superar las meras aproximaciones arqueográficas y explorar toda la potencialidad del registro material, nos han planteado numerosos problemas operativos y sobre todo conceptuales, al menos en lo que se refiere a su aplicación en el estudio de las sociedades feudales.

Ante la carencia de proyectos arqueológicos de un cierto calado (y no me refiero únicamente a una cuestión económica), no se han explorado nuevos caminos y creado nuevas infraestructuras para analizar registros básicos como los bioarqueológicos, que en el caso del estudio de los espacios de producción son absolutamente primordiales. En la actualidad hay muy pocos laboratorios en España que se dediquen a la Arqueobotánica o a la Arqueofauna, y curiosamente todos ellos operan mayoritariamente sobre contextos anteriores a la romanización. Solo en los últimos años se están realizando investigaciones básicas, fundamentales para el conocimiento de la agricultura y la ganadería altomedieval que están proporcionando resultados realmente relevantes para la comprensión de la economía y la sociedad de este período.

De igual manera, los restos materiales del campesinado han permanecido durante mucho tiempo ocultos a las investigaciones arqueológicas sobre las sociedades feudales, que han priorizado otro tipo de elementos de carácter más monumental, redimensionando la monumentalidad de la clásica Arqueología

16 Barceló, M., Kirchner, H., Lluró, J.M., Martí, R., Torres, J.M., Arqueología Medieval. En las afueras del «medievalismo», Barcelona, Crítica, 1988, págs. 196 y ss.

17 BARCEló, M., «Crear, disciplinar y dirigir el desorden. La renta feudal y el control del proceso de trabajo campesino: una propuesta sobre su articulación», Taller d'Història, VI, 2, Valencia, págs. 61-72, pág. 64. 
clásica a la medieval. De hecho, el utillaje metodológico disponible y las orientaciones de la investigación no han permitido en los últimos decenios ni siquiera localizar con facilidad las áreas de residencia campesina, de tal manera que contamos con menos de diez años de experiencia en la localización y en la comprensión de las unidades domésticas campesinas.

No obstante, en estos últimos diez años se ha producido una pequeña revolución silenciosa en lo que se refiere a los procedimientos y a los marcos conceptuales de intervención arqueológica en el ámbito de la Arqueología del Campesinado. Al menos en amplias zonas de la Meseta, y adoptando estrategias que en realidad se estaban utilizando desde hace tiempo en otros sectores europeos, han sido las empresas de Arqueología, menos condicionadas por las orejeras teóricas de la Academia, las que han empezado a trabajar en grandes extensiones, desbordando ampliamente el concepto tradicional de yacimiento ${ }^{18}$.

De esta manera hemos pasado de un concepto de Arqueología del paisaje, entendiendo éste como un constructo teórico en el que a partir de aportaciones multi/pluridisciplinares colocábamos al paisaje como objeto de estudio, a una intervención arqueológica del paisaje de carácter integral. Cuando una obra pública o un proceso de urbanización incide sobre grandes superficies y se logran excavar varias hectáreas de forma continua con las estrategias adecuadas se produce un cambio de escala y una nueva percepción del registro arqueológico que permite la construcción de documentos arqueológicos complejos. Entendemos por registro arqueológico complejo aquél formado por elementos relativamente simples pero que, analizados de forma conjunta, plantean problemas de orden diferente (superior) al que supone la mera adicción de sus partes. A través del uso de estos planteamientos podemos abordar desde una óptica sistémica la comprensión de las estructuras agrarias del pasado, formando parte de un orden social que es el que las explica y les da sentido.

Es desde esta óptica en la que queremos plantear que la que en su día fue una oportuna y necesaria contraposición entre el estudio de las áreas de residencia y los espacios de producción ha dejado de tener sentido desde este planteamiento. Ni los límites entre ambas esferas son tan netos, ni la separación operativa entre los dos ámbitos de estudio es útil para entender la complejidad de los procesos. Además, uno de los aspectos que más suspicacias ha planteado a la hora de analizar los espacios agrarios, esto es, la cronología de los campos de cultivo o las formas de estudiar las variaciones diacrónicas de las estructuras agrarias, se resuelve con mayor facilidad cuando operamos desde la globalidad de los paisajes y la comprensión de los SISTEMAS.

Por otro lado, un planteamiento más integral y globalizante permite abordar problemas de mayor calado. Las tradiciones de estudio europeas llevan años

18 FERNÁNDEZ UGALDE, A., «Metodología para el conocimiento de yacimientos extensos», en: Actas de las primeras jornadas de Patrimonio Arqueológico en la Comunidad de Madrid, Madrid, Comunidad de Madrid, 2001, págs. 39-53. 
estudiando fenómenos como la relación existente entre la formación de las aldeas concentradas y del sistema de los openfields ${ }^{19}$, la formación de los paisajes agrarios altomedievales a partir de evidencias bioarqueológicas ${ }^{20}$ o la relación entre la afirmación de estas aldeas y la implantación de sistemas de rotación de cultivos y el desarrollo de determinadas prácticas agrarias. Este tipo de preguntas aún no han sido siquiera formuladas en nuestro entorno, pero desde la óptica del estudio extenso del fenómeno aldeano adquieren todo su significado.

Es cierto que los proyectos arqueológicos en áreas extensas que se están desarrollando en los últimos años tampoco llegan a cubrir en toda su extensión (funcional y espacial) la territorialidad aldeana ni la complejidad de espacios como los forestales, los ganaderos o en ocasiones los comunales. Y es igualmente cierto que aún debemos aprender y depurar mucho nuestros instrumentos conceptuales para comprender las lógicas sociales que han modelado el paisaje. Por todos estos motivos las ideas que expondré a continuación no pueden considerarse más que provisionales a la espera de los numerosos trabajos e investigaciones que tenemos en marcha. Pero creo que se pueden replantear algunos aspectos básicos de las prácticas agrarias medievales.

Un último aspecto importante que hay que formular es la necesidad de integrar en el estudio de los paisajes agrarios la dimensión diacrónica, evitando describir o formular lógicas productivas aparentemente «fosilizadas» que han llegado hasta nuestros días. Este riesgo, que corremos especialmente aquéllos que operamos en despoblados o en ventanas cronológicas que no siempre se extienden hasta nuestros días, puede ser superado mediante la adopción de una aproximación de carácter regresivo, tal y como en su día lo planteó M. Bloch y ha sido desarrollado en varios proyectos arqueológicos ${ }^{21}$. En palabras de Diego Moreno,

«l'archeologia del paesaggio agrario potrebbe consistere nella ricostruzione della sequenza di tutte le diverse utilización che si sono succedute in un sito archeologico, stabilendone i rapporti con le trasformazioni delle strutture agrarie locali in età medievale e post-medievale»22.

\section{EJEMPLOS DE ANÁLISIS}

En esta ocasión centraremos nuestra atención sobre algunos conjuntos arqueológicos localizados en el territorio alavés que han sido analizados en con-

19 ReYNOLDS, A., Later Anglo-Saxon England. Life and landscape, London, Tempus, 2003, pág. 100.

20 RipPON, S., FYPE, R.M., BROWN, A.G., «Beyond villages and Open fields: The origins and development of a Historic landscape characterised by dispersed settlement in South-West England», Medieval Archaeology, 50 (2006), págs. 31-70.

21 Un ejemplo de aplicación ha sido Quirós Castillo, J.A., Archeologia e storia di un castello Apuano: Gorfigliano dal medioevo all'età contemporanea, Florencia, All'insegna del Giglio, 2004.

22 Moreno, D., Dal documento al terreno. Storia e archeoilogia dei sistemi agro-silvo-pastorali, Bologna, Il Mulino, 1990, pág. 163. 
textos muy diferentes en los últimos tres años (fig. 1). A través de estos ejemplos intentaremos discutir los problemas que plantea el análisis arqueológico de los espacios de producción agraria.

FIGURA 1. MAPA DEL PAÍS VASCO CON LAS PRINCIPALES LOCALIDADES MENCIONADAS EN EL TEXTO

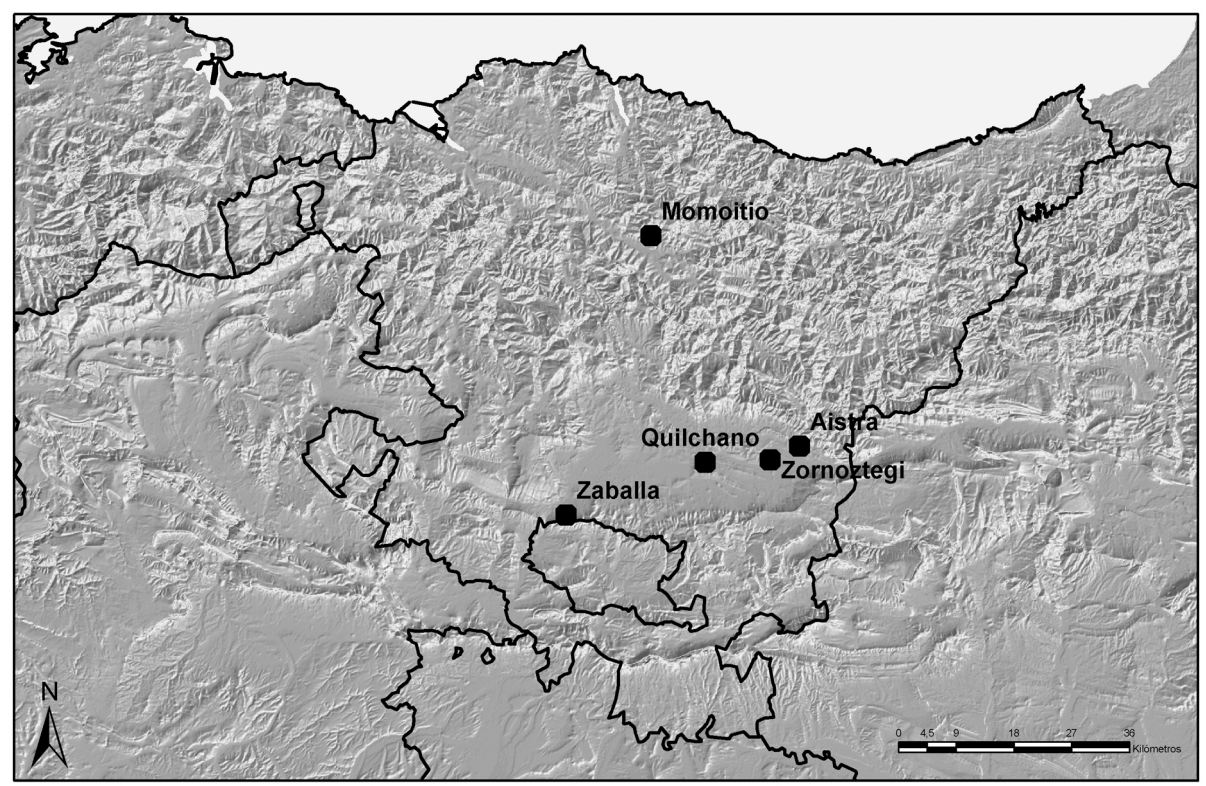

De forma previa hay que señalar que el estudio arqueológico de los espacios agrarios alaveses cuenta con un condicionante muy importante: las importantes modificaciones de los paisajes rurales que han tenido lugar en los últimos decenios. La concentración parcelaria iniciada en Álava a partir del 1956 en Eguileta, con la consiguiente mecanización de las prácticas agrarias, ha cancelado para siempre indicadores y elementos arqueológicos fundamentales para la comprensión de las prácticas agrarias medievales. El proceso de concentración tuvo un ritmo muy intenso durante los años 60 y 70, de manera que hacia mediados de los 80 se había intervenido en $70593 \mathrm{Ha}$, sobre todo en los Valles, la Montaña y en la llanada (tabla 1). En la Llanada alavesa, donde se concentran las evidencias arqueológicas aquí analizadas, se produjo entre los años 19561972 una reducción del número de parcelas del 85\% y una multiplicación por 6 de las dimensiones medias de cada explotación ${ }^{23}$.

23 Ruiz de Urrestarazu, E., Gabana Cuesta, A.G., Espacio y sociedad rural en Álava (19591986), Vitoria, Diputación Foral de Álava, 1990, págs. 71-75. 
TABla 1. NÚMERO DE PARCELAS Y EXTENSIÓN MEDIA DE LAS MISMAS EN LOS AÑOS 1956 Y 1972 EN ÁLAVA

\begin{tabular}{|c|c|c|}
\hline $25379 \mathrm{Ha}$ & Número de parcelas & Extensión media \\
\hline Año 1956 & 90460 & $0,28 \mathrm{Ha}$ \\
\hline Año 1972 & 13688 & $1,85 \mathrm{Ha}$ \\
\hline
\end{tabular}

FIGURA 2. FOTOGRAFÍAS AÉREAS DEL «VUELO AMERICANO» DEL AÑO 1956 Y DE la Diputación Foral de Álava (2005) DEL SECTOR DE LA ALDEA DE ZORNOZTEGI (SALVATIERRA), EN EL QUE SE OBSERVA LAS TRANSFORMACIONES EN LA PARCELACIÓN, RED DE CAMINOS Y CURSOS FLUVIALES

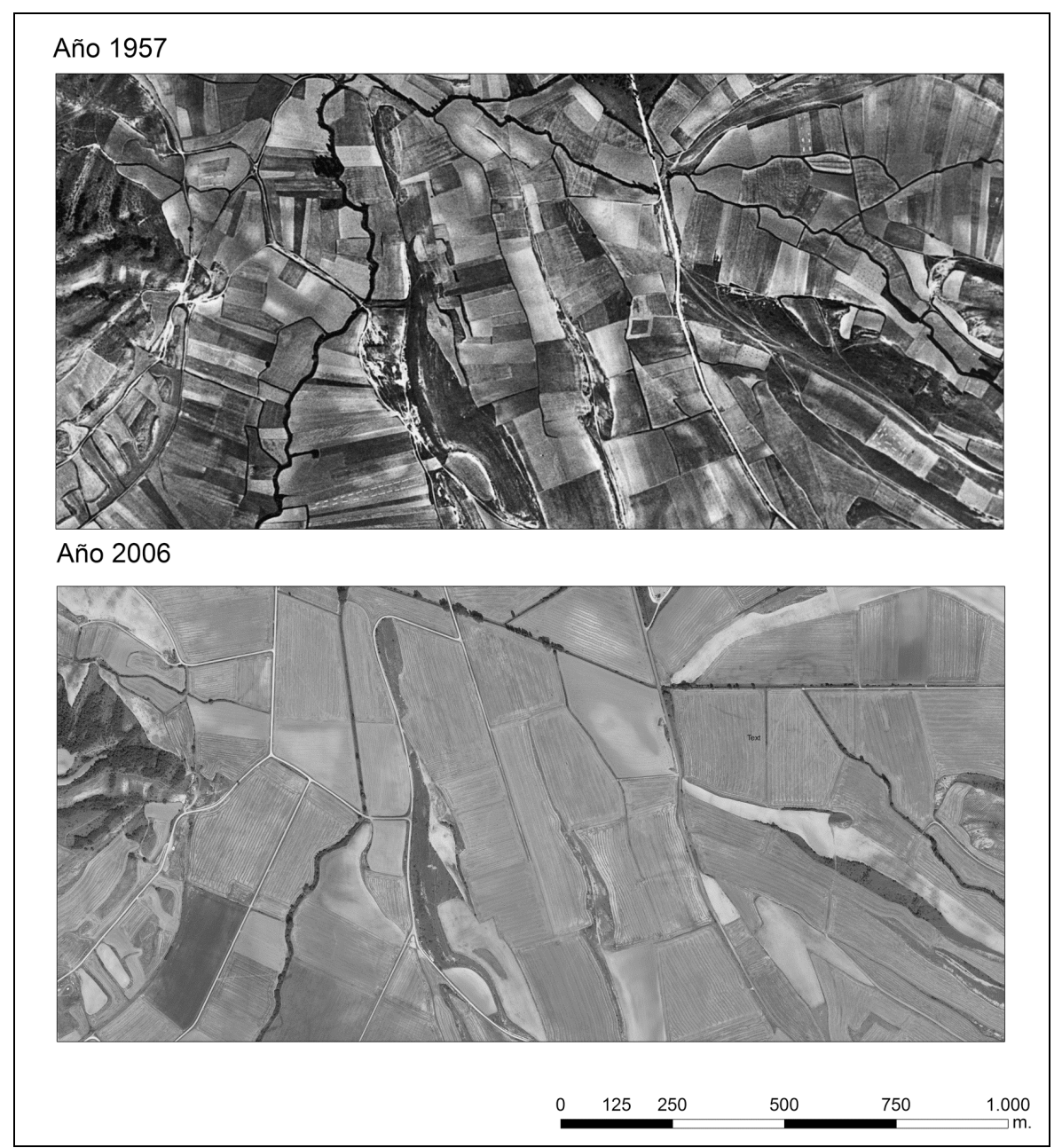

Hispania, 2009, vol. LXIX, nº. 233, septiembre-diciembre, 619-652, ISSN: 0018-214 
La comparación entre las fotografías aéreas de la Diputación Foral de Álava del año 1932 o del vuelo americano del año 1956 con las realizadas en los últimos decenios muestra hasta qué punto se ha perdido un patrimonio de notable importancia, tanto en lo que se refiere a la distribución parcelaria, como a las redes de caminos, desvíos de regatos y cursos de aguas, pero también en lo que se refiere a la microtoponimia y en general a los mapas mentales con los que las sociedades campesinas han ordenado, construido y percibido el paisaje (fig. 2). Vivimos, además, prácticamente con la última generación que atesora a través de la memoria oral aspectos básicos de los paisajes agrarios antiguos. Autores como Marco Milanese se han referido a este proceso de recopilación de la memoria oral como una verdadera «Arqueología de emergencia» ${ }^{24}$.

Teniendo en cuenta todos estos elementos, analizaremos en esta ocasión, y por motivos de espacio, únicamente tres temáticas concretas: la Arqueología de los espacios de cultivo; las formas de almacenaje y de tratamiento de los productos agrarios y las prácticas agrarias.

\subsection{Los espacios de cultivo}

En Álava, como en buena medida de casi todo el Norte Peninsular, la detección y el estudio de los campos de cultivo de época preindustrial se encuentra muy comprometida por las tareas más recientes. Un ámbito privilegiado para el estudio de estos espacios son las aldeas despobladas en las que, con frecuencia, el cambio funcional de las explotaciones o de las dedicaciones ha fosilizado, hasta un cierto punto, los campos de cultivo medievales. Hay que ser, no obstante, bastante prudentes a la hora de analizar este tipo de yacimientos, ya que en principio el despoblamiento de una aldea no comporta el abandono del terrazgo. Normalmente se mantiene en uso por parte de los mismos propietarios que se han desplazado a otras aldeas o villas cercanas, aunque en otras ocasiones lo que se produce es una quiebra completa del sistema, especialmente cuando se disgrega la comunidad que avala los usos comunitarios o semicomunitarios de algunos espacios de cultivo, y es entonces posible que se produzcan cambios profundos en los usos y las dedicaciones. En algunos de los despoblados que hemos estudiado que se sitúan en los pies de monte y en las zonas más marginales de la llanada alavesa, se ha podido constatar a través de la documentación escrita de época bajomedieval, moderna y contemporánea, la transformación de espacios de cultivo en espacios de carácter preferentemente ganadero.

A priori, y en términos estrictamente arqueológicos, la detección de los campos de cultivo en lugares donde se ha producido una intensa concentración parcelaria y se han perdido las referencias espaciales se produce a partir del hallazgo en las prospecciones de superficie de aquéllos residuos domésticos que

24 Milanese, M., «Voci delle cose: fonti orali, archeologia postmedievale, etnoarcheologia», Archeologia Postmedievale, 9 (2005), págs. 11-30. 
por su carácter no orgánico perduran a lo largo del tiempo. En las parcelas cercanas a los pueblos actuales es fácil localizar cantidades significativas de materiales cerámicos de distintos períodos dispuestos sin formar concentraciones reveladoras, que son claramente indicadoras de estas prácticas de abonado basadas en el aprovechamiento de los residuos domésticos. Es bien conocido, de hecho, la práctica del abonado en las parcelas más cercanas a las viviendas mediante los residuos domésticos. Mientras que la mayor parte de estos residuos son orgánicos, y por lo tanto son absorbidos por el terreno, la cerámica es un residuo que no se degrada y se conserva durante mucho tiempo.

Estos off-sites ${ }^{25}$ han sido detectados con frecuencia en las prospecciones realizadas en la llanada alavesa en lugares como Ayala, Quilchano, Elguea, Zalduondo, etc. (fig. 3).

Pero también es significativo señalar que en proximidad de los despoblados medievales suele ser frecuente que los únicos materiales cerámicos hallados resultado de este proceso de abonado pertenezcan a períodos cronológicos muy concretos. Bien porque el proceso de abonado con residuos domésticos se sustituye por el abonado mediante el ganado cuando las unidades domésticas ya no se encuentran cercanas, bien porque — como se ha señalado- se ha producido un cambio en la dedicación y en la naturaleza de la explotación. Esto se ha podido detectar tanto en despoblados como Quilchano o Ayala, donde en los márgenes de las parcelas donde se encuentran los escombros de las viviendas de la aldea solamente se encuentran cerámicas dispersas sin vidriar, o en el valle de Zaballa. En este despoblado, que ha sido excavado integralmente, el abandono de la aldea en el siglo XV dio paso a un uso ganadero del espacio hasta mediados del siglo $\mathrm{XX}$, cuando se produjo el desbroce parcial de zonas de pasto arbolado.

Pero estos indicadores, en realidad, poco ayudan a delimitar con precisión la extensión de los espacios cultivados o a comprender la naturaleza de las prácticas agrarias medievales, teniendo en cuenta además que no son sino fragmentos de parcelas definidas en los últimos decenios. Son, de alguna manera, los últimos testimonios de la existencia de campos de cultivo de épocas pasadas. Con todo, comprender su naturaleza y la ubicación de estos campos de cultivo medievales sigue teniendo una importancia clave a la hora de comprender el paisaje aldeano ${ }^{26}$.

25 Los espacialistas denominan off-sites o non sites a aquellas dispersiones de materiales arqueológicos situadas en los campos que no conforman concentraciones significativas (CAMBI, F., Terrenato, N., Introduzione all'archeologia dei paesaggi, Roma, Carocci, 1994, págs. 168-174). El hallazgo de materiales arqueológicos en superficie de muchos períodos debido a la mecanización de las tareas agrícolas es el resultado de una intensa actividad de destrucción de depósitos del subsuelo. Durante mucho tiempo se ha pensado que estos materiales indicarían «ruido de fondo» poco significativo. La comprensión de los procesos de abonado mediante el empleo de residuos domésticos producidos en los campos situados en proximidad de las propias viviendas a llevado a una revalorización de este tipo de hallazgos.

26 Recientemente, en la excavación del despoblado de Guernica (Arrazua-Ubarrundia, VitoriaGasteiz), se realizaron siete catas de dos por dos metros en las que se localizaron "puntualmente 
Figura 3. DisTRIBUCIÓN CUANTITATIVA DE CERÁMICAS DE ÉPOCA MEDIEVAL Y MODERNA EN EL ENTORNO DEL DESPOBLADO DE QUILCHANO (ELBURGO, ÁLAVA), RESULTADO DE LOS PROCESOS DE ABONADO MEDIANTE EL EMPLEO DE RESIDUOS DOMÉSTICOS

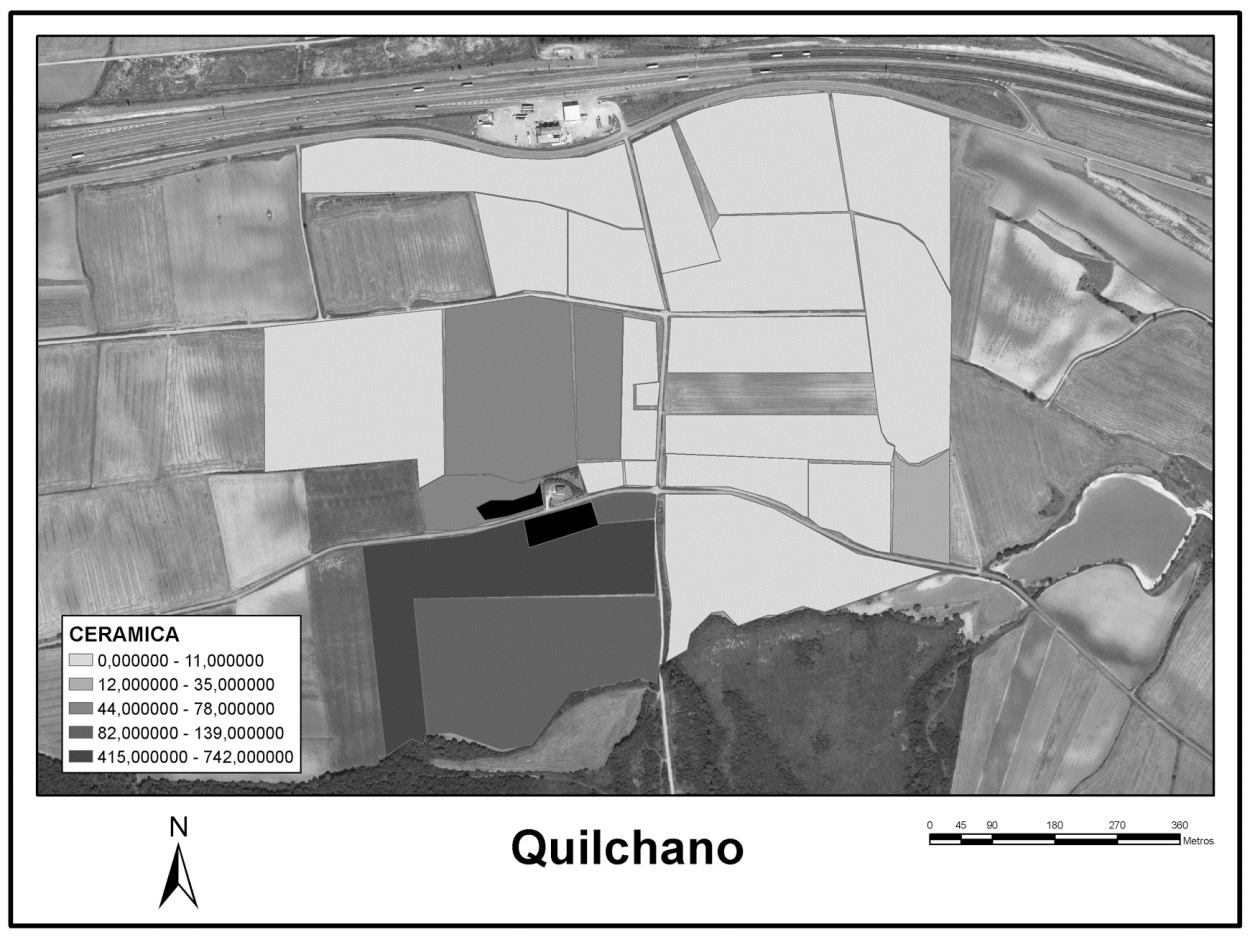

Pero más allá de los problemas que presenta la interpretación y el estudio de la dispersión de los residuos domésticos medievales utilizados como abono, una de las aportaciones más importantes que ha proporcionado el estudio integral del fenómeno de los despoblados medievales alaveses ha sido el reconoci-

fragmentos de cerámica torneada vidriada y sin vidriar de factura postmedieval» y estratos en el que se «recogieron escasos restos de cerámica torneada sin vidriar de factura medieval y postmedieval (...) (e incluso uno sin tornear)» (FIlloY, I., «Despoblado de Guernica (Arrazua-Ubarrundia; Vitoria-Gasteiz; Zigoitia)», Arkeoikuska, 06 (2007), pág. 248). Todos los niveles se consideraron como niveles removidos «sin interés arqueológico» porque no se halló «un registro deposicional de carácter arqueológico, ni adscribibles a este yacimiento». Se concluyó entonces que el despoblado se debería de encontrar en las proximidades de esta zona, pero no en el área afectada por las obras. A partir de nuestra experiencia de campo podemos determinar que los arqueólogos que trabajaron en este yacimiento (que no es una excepción), estuvieron excavando campos de cultivo medievales y postmedievales abonados con residuos domésticos. Además, sabemos que en este tipo de yacimientos la proximidad entre los espacios habitados y los campos abonados (visibles a través de este tipo de residuos) es inmediata. 
miento de espacios de cultivo aterrazados, que en ocasiones se han preservado ya que las pendientes en las que se sitúan son demasiado acusadas para haber sido afectadas por la concentración parcelaria, los suelos en los que han sido realizados son demasiado pobres como para haber sido integrados en la parcelación, o bien porque han sido reconocidos durante los procesos de excavación en áreas extensas.

En realidad, el estudio de los espacios aterrazados ha merecido una cierta atención por los arqueólogos de época histórica en los últimos años, y los trabajos realizados por M. Ruiz del Árbol en la Sierra de Francia o P. Ballesteros en Galicia han permitido definir un instrumental metodológico y unos planteamientos de análisis que sirven de referencia para abordar el estudio de estos terrazgos ${ }^{27}$. Más concretamente en la Sierra de Francia se ha podido comprobar la importancia en época romana de los sistemas aterrazados en las zonas de montaña, y en el caso gallego se ha podido demostrar que la construcción de los terrazgos campesinos actuales tuvo lugar durante la Alta Edad Media en el contexto de la creación de redes de aldeas estables que han perdurado hasta nuestros días.

En el caso alavés los datos con los que contamos hasta el momento son bastante impactantes. Aunque en la actualidad se está realizando una revisión completa de los 308 despoblados del territorio ${ }^{28}$, hay que constatar que en todos los despoblados en los que hemos realizado intervenciones arqueológicas de una cierta extensión se ha podido constatar la existencia de espacios de cultivo aterrazados fechables con certeza en el período medieval.

Antes de analizar con detalle algunos de los ejemplos más significativos con los que contamos, es preciso hacer una serie de valoraciones previas. El estudio de las terrazas, como en general de todos los espacios de cultivo, plantea una serie de problemas de orden metodológico:

1. Tal y como han planteado P. Ballesteros, es necesario diferenciar aquéllos bancales creados de forma no intencional o natural o que han sido creados mediante la acumulación continua de diferentes depósitos (terraza intencional progresiva), respecto a las terrazas o bancales realmente construidos mediante la aportación intencional de importantes rellenos por parte de la comunidad campesina con el fin de crear estructuras producti-

27 Ballesteros Arias, P., La arqueología de la gasificación en Galicia 17: El paisaje agrario, Santiago de Compostela, CAPA 18, CSIC, 2003; RUIZ DEL Árbol MORO, M., La arqueología de los espacios cultivados. Terrazas y explotación agraria romana en un área de montaña: la Sierra de Francia (Salamanca), Madrid, CSIC, 2005.

28 Una síntesis reciente sobre la arqueología de las aldeas alavesas se puede ahora consultar en Quirós Castillo, J.A., «Las aldeas altomedievales en el País Vasco», en: Quirós Castillo, J.A. (ed.), Archaeology of villages in Early Medieval Ages, Bilbao, Universidad del País Vasco, 2009, págs. 387-405. 
vas estables (terraza sistemática o monumental) ${ }^{29}$. El reconocimiento y estudio de estas morfologías, que comportan obviamente prácticas sociales muy diferentes, requiere necesariamente la excavación mediante trincheras perpendiculares a las pendientes de los espacios agrarios y habitados, como instrumento operativo para comprender los procesos formativos de las secuencias estratigráficas y las prácticas agrarias. Contamos ya con una amplia serie de experiencias tanto en Europa como en España en contextos de época histórica suficientemente validados como para comprender la potencialidad y las limitaciones de este tipo de estudios ${ }^{30}$.

2. Un segundo aspecto que hay que considerar es el tipo de estrategia de estudio en el que se sitúa el análisis de los espacios cultivados. Es decir, en los paisajes agrarios del norte peninsular los sistemas de terrazas se presentan como el elemento más visible y/o monumental de los espacios agrarios que podemos reconducir al período medieval o incluso anterior. Esta identidad ha llevado a que en algunas ocasiones fuese necesario o posible analizar este tipo de estructuras de forma aislada del resto del paisaje o tratarlas como un elemento diferenciado del resto de los espacios aldeanos (y en primer lugar de los denominados espacios de residencia). Las consecuencias de esta disociación son varias; en primer lugar, en términos de comprensión sistémica del funcionamiento de los procesos de construcción y reconfiguración social del paisaje; en segundo lugar, en términos de datación de las propias terrazas (problema que ha sido al menos parcialmente resuelto en experiencias realizadas en Galicia), y que con frecuencia termina por resolverse en términos de proximidad entre los espacios residenciales y de producción. La intervención integral, combinando el estudio de ambos espacios permite resolver este problema con una cierta facilidad. Un caso significativo es el del yacimiento romano de Fuente de la Mora (Sierra de Francia, Salamanca), en cuya proximidad se han realizado toda una serie de sondeos cortando las terrazas agrarias en las que se ha podido constatar la existencia de rellenos intencionales en los que eran frecuentes las basuras domésticas producidas por el asentamiento romano ${ }^{31}$.

3. En tercer lugar, es muy importante que logremos avanzar en el desarrollo de protocolos de análisis sistemáticos de los espacios de cultivo a la hora de comprender fenómenos como los procesos formativos de las pro-

29 BALlesteros, P., La arqueología de la gasificación..., pág. 28.

30 Un ejemplo es el estudio de los paisajes rurales de Anteggi (Génova), MorENO, Dal documento al terreno..., págs. 170-180, o el de la sierra de Marina en Badalona, RIERA MORA, S., PALET MARTíneZ, J.M., «Una aproximación multidisciplinar a la historia del paisaje mediterráneo: La evolución de los sistemas de terrazas con muros de piedra seca en la sierra de Marina (Badalona, Llano de Barcelona)», en: Garrabou, R., NAREDO, J.M. (eds.), El paisaje en perspectiva histórica. Formación y transformación del paisaje en el mundo mediterráneo, Zaragoza, Universidad de Zaragoza, 2008, págs. 47-90.

31 RuIz Del ÁrbOL MORO, La arqueología de los espacios cultivados..., págs. 85-96. 
pias terrazas o las prácticas agrarias que han tenido lugar. Contamos ya con un repertorio de técnicas arqueométricas muy desarrolladas que han demostrado su utilidad a la hora de comprender aspectos básicos de los espacios de cultivo medievales. No obstante, y por toda una serie de circunstancias, aún no se han aplicado de forma sistemática a las terrazas medievales. Sabemos que el estudio de indicadores químicos ( $\mathrm{N}, \mathrm{Ca}, \mathrm{K})$ permite comprender las prácticas de abonado y el empleo de materiales orgánicos como fertilizantes ${ }^{32}$, o que los estudios micromorfológicos permiten analizar tanto los procesos formativos de las terrazas (que no olvidemos que son depósitos secundarios), así como prácticas como el arado, la irrigación, los usos agrarios o ganaderos, los procesos postdeposicionales, etc. ${ }^{33}$. Ahora mismo se están experimentando en los terrazgos medievales alaveses este tipo de procedimientos y esperamos poder contar en tiempos relativamente reducidos con resultados.

4. Por último, otro aspecto que hay que tener en cuenta es que hay que crear propuestas y modelos de análisis social de la construcción de los espacios de cultivo en la Edad Media: ¿cómo explicamos que en la Alta o en la Plena Edad Media comunidades aldeanas enteras se coordinen para movilizar centenares de metros cúbicos de tierra con los que crear sistemas de terrazas en las que cultivar cereales? ¿Son procesos «espontáneos» inherentes a las lógicas de las sociedades campesinas o son fenómenos promovidos y estimulados por un poder que precisa la generación de excedentes, la modificación de los espacios de cultivo o la reordenación de las prácticas productivas?

Teniendo en cuenta todas estas inquietudes, pasaremos ahora a exponer brevemente los registros arqueológicos disponibles actualmente en Álava. Nos centraremos solamente en tres ejemplos concretos, aunque se están analizando otros conjuntos en los que encontramos problemas similares. Ordenaremos en términos cronológicos las evidencias arqueológicas con las que contamos ${ }^{34}$.

\subsubsection{Aistra}

Hasta el momento los espacios aterrazados más antiguos que hemos detectado en el País Vasco se sitúan en el despoblado de Aistra (Zalduondo). Este

32 Ruiz del Árbol Moro, La arqueología de los espacios cultivados..., pág. 99.

33 Courty, M.A., Goldberg, P., MacPhail, R., Soils and micromorphology in Archaeology, Cambridge, Cambridge University Press, 1989, págs. 126-137.

34 En esta ocasión se realiza una breve presentación de cada uno de los contextos, ya que en la actualidad se están redactando las monografías que recogen de forma exhaustiva los trabajos arqueológicos realizados en estos yacimientos. 
yacimiento, situado en la llanada oriental alavesa, está siendo excavado en colaboración con la University College of London, y hasta el momento únicamente se ha intervenido en unos $3500 \mathrm{~m}^{2}$ aproximadamente, aunque se ha evaluado y sondeado un espacio más amplio.

El yacimiento ocupa una plataforma elevada de unas $13 \mathrm{Ha}$ presidida por la ermita altomedieval de San Julián y Santa Basilisa de Aistra (fig. 4).

FIGURA 4. ViSTA GENERAL DE LAS EXCAVACIONES ARQUEOLÓGICAS DEL DESPOBLADO DE Aistra (ZALDUONDO, ÁlAVA), AgOSTO 2009

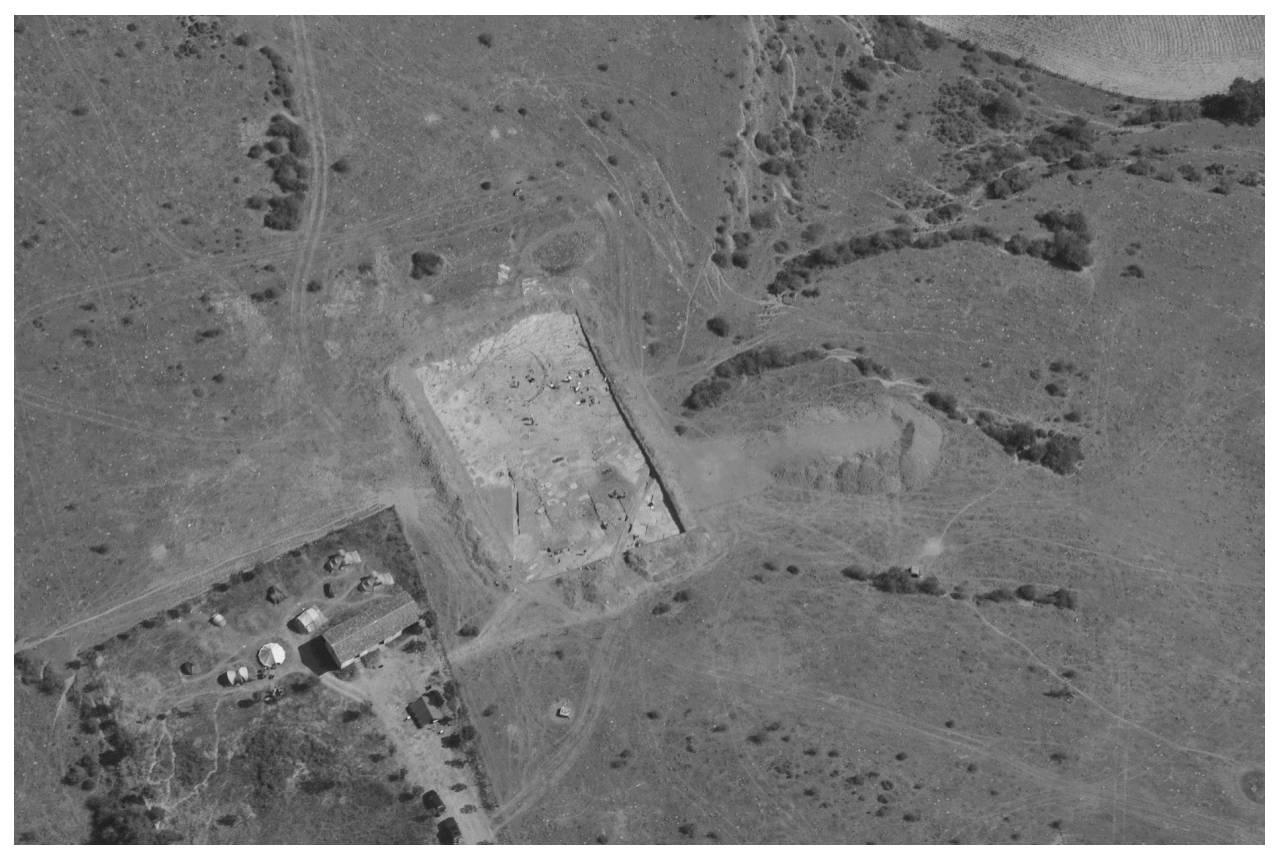

Fotografía de F. Didierjean, Instituto Ausonius (Université Michel de Montaigne- Bordeaux III) y ANR (Agence Nationale pour la Recherche).

La aldea de Aistra fue fundada hacia el siglo VI en proximidad de un yacimiento romano. Sin pretender extendernos demasiado en su secuencia ocupacional, hay que señalar que hasta el momento se han localizado una serie de estructuras semienterradas de planta irregular rellenadas con materiales cerámicos tardorromanos, y algunos silos. La amortización final de estas estructuras tuvo lugar hacia el 665-68035, cuando se construyeron en su proximidad una serie de

35 Datación radiocarbónica de uno de los rellenos de amortización: unidad estratigráfica 527 (DSH 771) $1241 \pm 32 \mathrm{BP}, 685-874 \mathrm{cal} \mathrm{AD} \mathrm{(95 \% ).}$ 
viviendas realizadas sobre postes o con rozas para el encaje del entramado de las paredes de las construcciones. Los primeros postes debieron de sustituirse una generación después, ya que el relleno de uno de ellos ha podido ser fechado hacia el 680-72036. A diferencia de otras aldeas similares excavadas en el País Vasco, estas viviendas fueron reconstruidas en varias ocasiones en el mismo lugar, mostrando la existencia de una notable ordenación y planificación del espacio. Se han logrado identificar al menos tres viviendas; una alargada dividida en tres espacios de unos $110 \mathrm{~m}^{2}$; una circular realizada con una roza perimetral y algunos postes centrales; una tercera a forma de barca. Al sur de estas viviendas se ha realizado un amplio cementerio, que fechamos provisionalmente entre los siglos VIII y IX, formado por unas 70 tumbas aproximadamente.

Ya en el siglo $\mathrm{X}$ se construyeron al sur de estas estructuras otras viviendas sobre postes y la ermita de San Julián y Santa Basilisa, que todavía se conserva en la actualidad ${ }^{37}$ (fig. 5).

Unos cincuenta metros hacia el oeste de toda estas estructuras altomedievales se ha reconocido la existencia de una serie de ocho bancales que tienen unos 7-10 m de anchura y unos $240 \mathrm{~m}$ de desarrollo lineal. Los bancales presentan taludes de $45^{\circ}$ con alturas inferiores al medio metro. Todo este terrazgo cubre un espacio agrario de poco más de $3 \mathrm{Ha}$, y se encuentra netamente separado del espacio ocupado por las viviendas. Teniendo en cuenta la escasa pendiente que presenta la ladera y el poco espesor de los suelos, pensamos que estas terrazas han sido realizadas con el fin de construir suelos agrarios dotados de una potencia adecuada para el cultivo cerealícola.

El estudio estratigráfico de las terrazas, que ha sido realizado por el Laboratorio de Arqueoloxia del Paisaje y Formas Culturales de la Universidad de Santiago de Compostela, ha determinado que para su realización se produjo una modificación integral del suelo original. El proceso formativo de estas terrazas fue definido como resultado de un proceso de desmonte de la ladera con relleno sistemático ${ }^{38}$, es decir, sin alterar el grado de pendiente, por lo que se depositó en un mismo momento el sustrato de tierra necesario para la configuración del aterrazamiento de una sola vez. Esta técnica es la que hemos documentado en

36 Datación radiocarbónica de la unidad estratigráfica 514 (DSH 779), $1283 \pm 38$ BP, 657783 cal AD (93\%). Una discusión más completa sobre la calibración de estas dataciones radiocarbónicas y el empleo de la estadística Bayesiana se puede consultar en QuiRós CASTILLO, J.A., «Las dataciones radiocarbónicas de yacimientos de época histórica. Problemas y experiencias de análisis en contextos de época medieval», Munibe, en prensa.

37 Datación de los rellenos de los postes de las viviendas: unidad estratigráfica 149 (DSH 345), $1013 \pm 19 \mathrm{BP}, 989-1032 \mathrm{cal}$ AC (95\%); unidad estratigráfica 144 (DSH 344), 1071 \pm 18 BP, 899$919(18 \%), 948-1018(82 \%)$ cal AC.

38 Utilizaremos los criterios de análisis y la terminología definida en BALLESTEROS ARIAS, P., CRIADO BoAdo, F. y ANDRADE, J.M., «Formas y fechas de un paisaje agrario de época medieval: A Cidade da Cultura en Santiago de Compostela», Arqueología Espacial, 26 (2006), págs. 193-226, pág. 210. 
la mayor parte de los ejemplos que hemos estudiado en los despoblados del País Vasco.

Figura 5. Vista de las terrazas agrarias de Aistra (ZalduONdo, Álava) en CURSO DE EXCAVACIÓN, FECHADAS ENTRE LOS SIGLOS V-VI

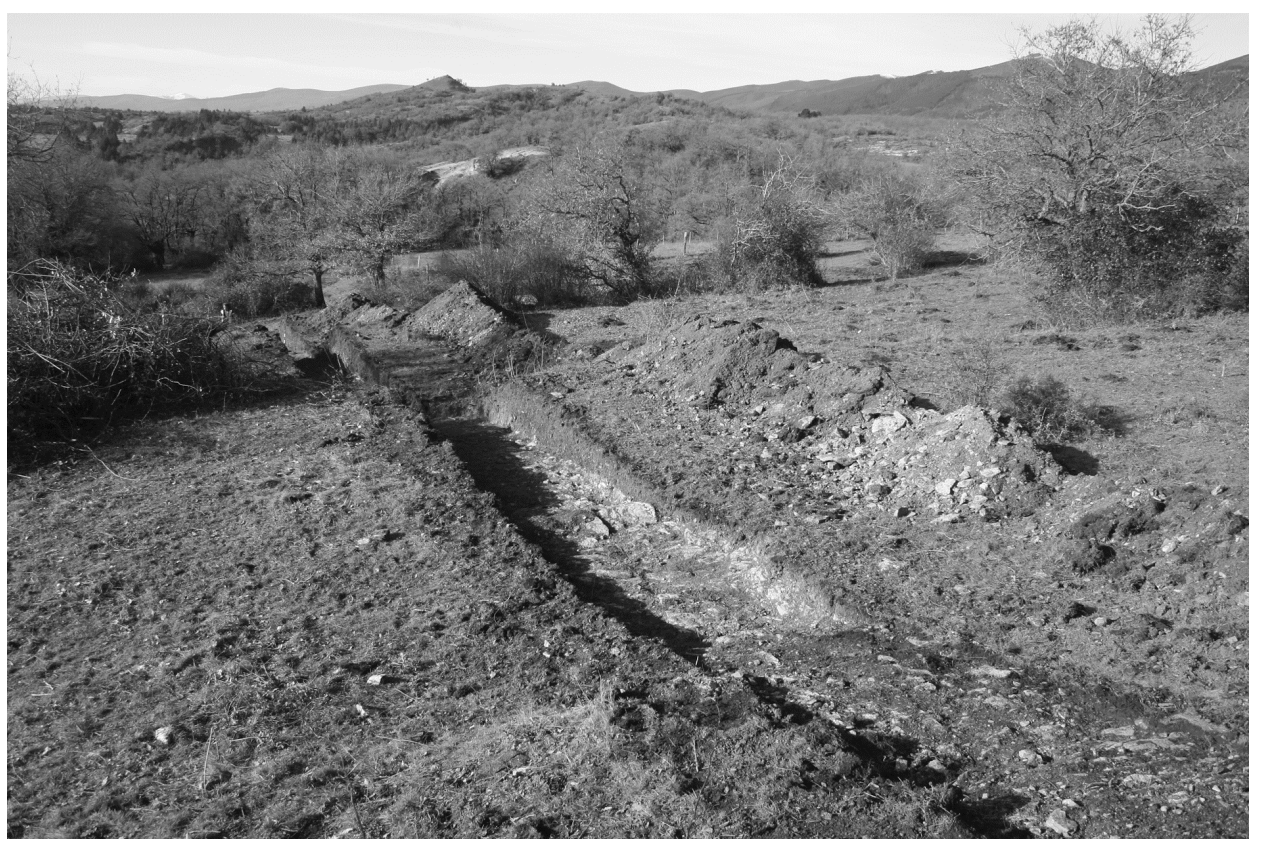

Las excavaciones realizadas en las terrazas han mostrado que pertenecen a momentos diferentes. En el sector cercano a la ermita de San Julián, se han hallado en los rellenos de las terrazas cerámicas esmaltadas, que sugieren que la realización de estos bancales pudo tener lugar hacia los siglos XVII o XVIII. En cambio, en el sector más alejado de la ermita donde se han excavado cinco de estos bancales, se han obtenido muestras orgánicas en la base de los rellenos de las terrazas para su datación radiocarbónica. Las dataciones realizadas han permitido fechar la colocación de estos rellenos entre los siglos $\mathrm{V}$ y VI ${ }^{39}$. Podemos concluir, por lo tanto, que estas terrazas fueron realizadas en el mismo momento en el que fundó la primera ocupación medieval del yacimiento.

39 Datación radiocarbónica del relleno de la terraza 3 (DSH783) 1568土31 BP, 421-559 Cal AC $(95 \%)$. 


\subsubsection{Zornoztegi}

El yacimiento de Zornoztegi (Salvatierra, Álava), se sitúa sobre una colina alargada formada por un sector superior de monte bajo que ha escapado milagrosamente a la concentración parcelaria por las acusadas pendientes que presenta, y un segundo sector escalonado que ha sido intensamente modificado por las prácticas agrarias que han tenido lugar en esta zona a partir de los años sesenta. En la actualidad se ha intervenido sobre una superficie equivalente a una hectárea, aunque también se ha evaluado otra media hectárea que ha sido intensamente alterada en los últimos años (fig. 6).

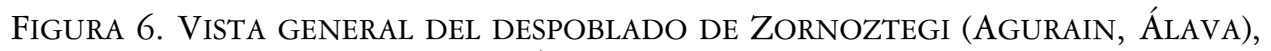
DONDE SE OBSERVA LA LOCALIZACIÓN DE LAS VIVIENDAS DEL SIGLO V, LA IGLESIA DE SANTA MARÍA (S. XII) Y LA PLATAFORMA DONDE SE HAN HALLADO LAS ESTRUCTURAS DOMÉSTICAS ALTOMEDIEVALES (SIGLOS VIII-XI)

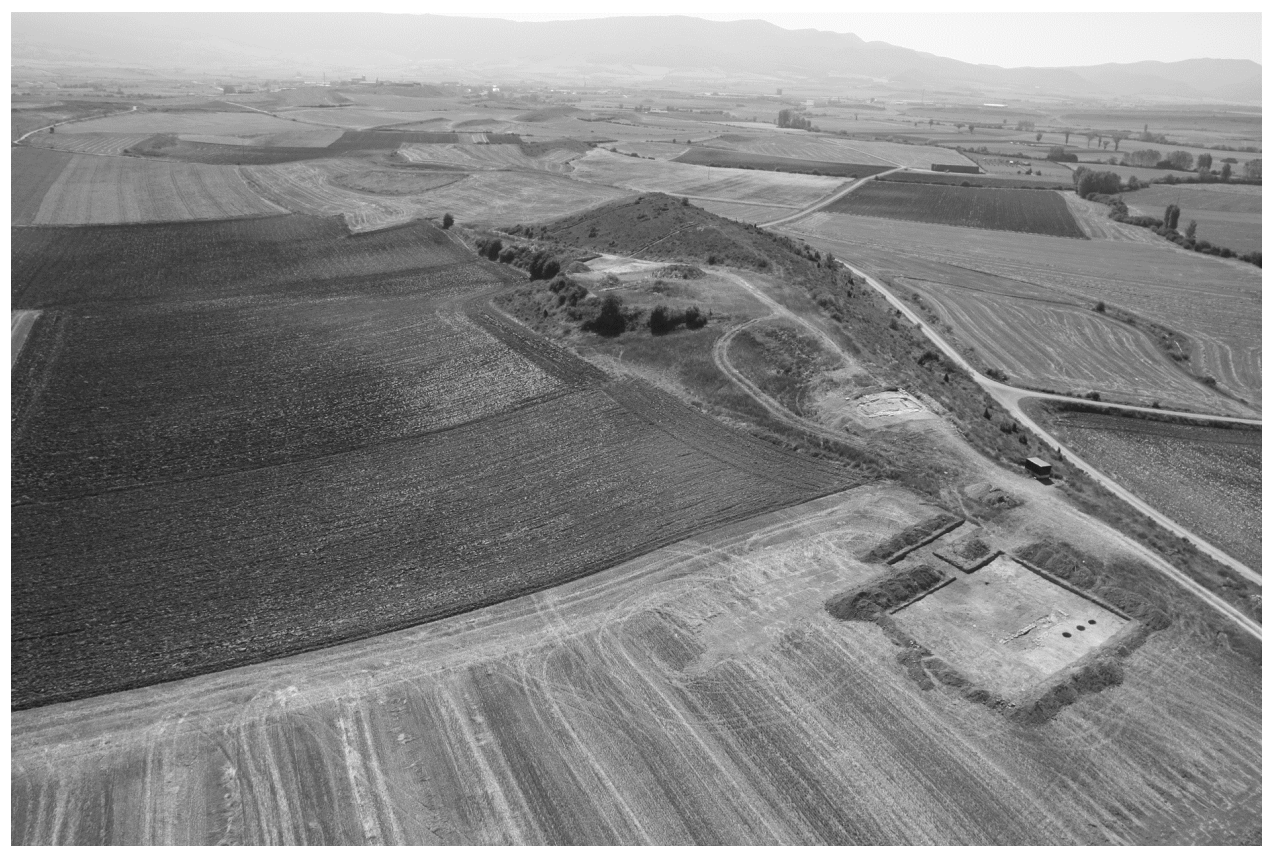

Narrando de forma muy sucinta su secuencia estratigráfica diremos que Zornoztegi cuenta con una amplia secuencia ocupacional. Las evidencias arqueológicas más antiguas datan de la Edad del Bronce, a la que pertenecerían un fondo de cabaña y un silo excavado en el extremo meridional de la colina de Zornoztegi. Nuevamente el yacimiento fue ocupado en el período romano, ya que se 
han encontrado en el extremo septentrional de la colina dos viviendas realizadas con zócalos de piedra atribuidas a este período y amortizadas en el siglo V.

Aparentemente sobre el abandono de esta granja tardorromana ${ }^{40}$ se ha fundado hacia el siglo VIII una amplia aldea que cubre una extensión aproximada de 1,2 Ha. Una estimación aún provisional nos lleva a pensar que sería una aldea formada por una docena de unidades domésticas que ocuparon toda la colina de Zornoztegi y la base donde se localizaban las estructuras romanas.

Durante los siglos VIII-XI estas unidades domésticas fueron profundamente transformadas mediante la reconstrucción con ciclos generacionales de las viviendas y las estructuras domésticas. Únicamente los límites entre las unidades domésticos y los sectores de almacenaje parecen haber tenido una amplia duración.

Fue en el siglo XI cuando se produjo una transformación del espacio aldeano. Las unidades domésticas situadas en el tramo meridional de la colina de Zornoztegi ${ }^{41}$ se amortizaron y las viviendas se concentraron en el extremo septentrional, donde luego se construiría en el siglo XII la iglesia de Santa María de Zornoztegi ${ }^{42}$.

En el tramo meridional, donde se localizaban toda una serie de viviendas, silos, cubetas y estructuras altomedievales, se construyeron en el siglo $\mathrm{XI}^{43}$ una serie de bancales de uso agrario que amortizaron estos elementos de carácter doméstico. Se han reconocido tres de ellos, tienen una anchura de unos 9-10 m y una longitud mínima de $42 \mathrm{~m}$., adaptándose a la morfología irregular del sustrato rocoso. Como en el caso de Aistra, el proceso formativo de estas terrazas no alteró la pendiente existente, y se realizaron mediante un proceso de desmonte de la ladera con relleno sistemático dispuesto directamente sobre el nivel de abandono doméstico previo. Los rellenos tienen potencias variables, y se han localizado derrumbes en la excavación que podrían pertenecer a muros o paramentos de sujeción de los frentes de los bancales. Una primera estimación nos permite pensar que se movilizaron entre $1600-1800 \mathrm{~m}^{3}$ de tierra con el fin de crear estos espacios agrarios (fig. 7).

Justo por encima de este terrazgo, en la ladera occidental de la colina que presenta una pendiente mucho más acentuada, las excavaciones han mostrado la construcción de bancales formados por rebajes de pequeña entidad destinados a nivelar superficies de no más de $1 \mathrm{~m}$ de profundidad que pudieron emplearse para cultivos que no requieren de suelos muy profundos, como por

40 Nuevos análisis radiométricos en curso deberán establecer si ha existido o no una solución de continuidad entre la granja tardorromana y la aldea altomedieval.

41 Datación de una de las estructuras, unidad estratigráfica 1949 (DSH 1111), 992-1052 (60\%), 1081-1128 (31\%), 1134-1152 (9\%) cal AD.

42 La iglesia de Santa María de Zornoztegi está documentada en el siglo XV, pero fue construida sobre una estructura previa de uso doméstico: unidad estratigráfica 1235 (DSH 1112), $954 \pm 24 \mathrm{BP}, 1023-1059(30 \%), 1064-1155$ (70\%) cal AD.

43 Datación de la base del relleno agrícola, unidad estratigráfica 1784 (DSH 1109), $960 \pm 23$ BP, 1021-1058 (33\%), 1076-1154 (65\%) cal AD. 
ejemplo los frutales. Esta es, de hecho, una práctica todavía hoy bien documentada en varios sectores alaveses. Estos bancales parecen haber sido realizados mediante un proceso de desmonte de ladera con relleno episódico.

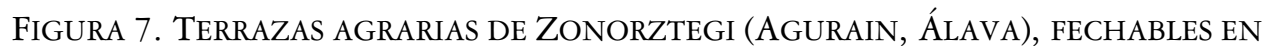
EL SIGLO XI

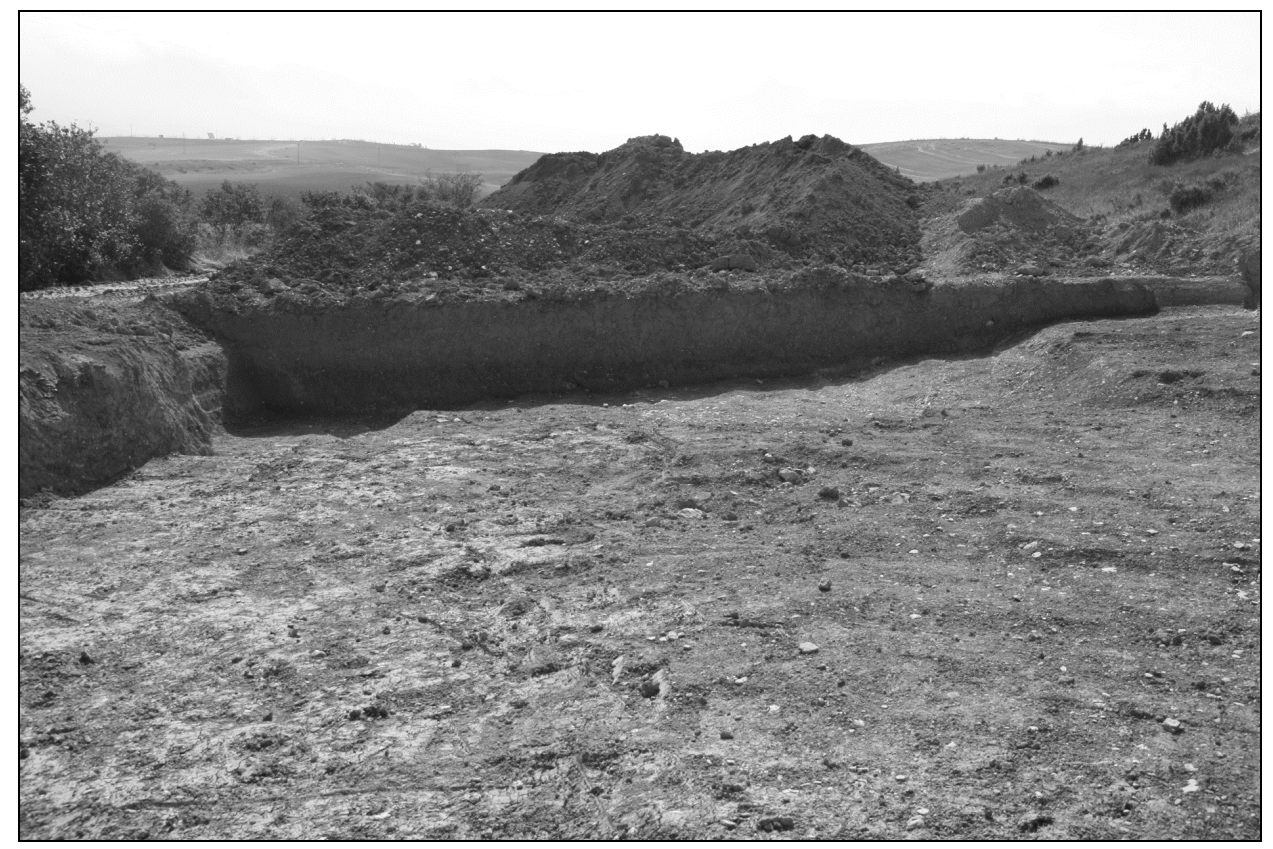

\subsubsection{Zaballa}

Nuestro último ejemplo analizado será el despoblado de Zaballa, cuya excavación acaba de concluirse. La realización de obra pública de interés general de grandes dimensiones ha comportado la excavación integral de un espacio aldeano, llegando a afectar casi 4,5 Ha. La calidad del registro arqueológico obtenido permite realizar un análisis exhaustivo de la microhistoria de esta aldea.

El yacimiento se ubica en la ladera septentrional de los Montes de Vitoria, ocupando parte de un profundo valle que alcanza la llanada alavesa en su tramo SW. La aldea medieval se estructura en torno a un fondo de valle central de unos $13000 \mathrm{~m}^{2}$, la ladera occidental donde se encuentran una serie de terrazas agrarias, la ladera oriental, que presenta pendientes más acusada y donde se ubica únicamente una gran terraza agraria, y una plataforma elevada situada en el tramo final del valle, de unos $5000 \mathrm{~m}^{2}$. 
La aldea de Zaballa, citada en la mencionada «Reja de San Millán» en el año 1025, aparece de forma muy esporádica en las fuentes escritas, y aunque se abandona en la Baja Edad Media, el topónimo se mantiene asociada a una Venta situada en el trazado del camino que se dirigía a Madrid por las Conchas de Arganzón.

De forma previa a la intervención arqueológica el yacimiento estaba definido como una Zona de Presunción Arqueológica que cubría una amplia extensión de unas $46 \mathrm{Ha}$ que de forma solamente marginal tocaba el yacimiento. La detección del yacimiento fue posible gracias al hallazgo, en el fondo del valle, de cerámicas medievales fragmentadas carentes de depósitos arqueológicos asociados y que generalmente se clasifican como materiales revueltos. De hecho, son muy numerosos los informes de prospecciones y seguimientos de obra que menciona el hallazgo de estos materiales sin lograr darles un sentido.

Para comprender mejor la entidad de las estructuras agrarias halladas en este yacimiento, será preciso recorrer su secuencia ocupacional, teniendo en cuenta que la ocupación del yacimiento durante un milenio ha hecho que sean más legibles las fases más recientes, y que en cambio una parte significativa de las estructuras más antiguas hayan sido destruidas (fig. 8):

Figura 8. Vista GENERAL DEL VAlle DEL DESPOBlado DE Zaballa (IRUÑA DE OCA, ÁlAVA), EN EL QUE SE APRECIAN LAS VIVIENDAS DEL SIGLO XIII Y LOS RELLENOS AGRARIOS DISPUESTOS EN EL FONDO DE VALLE

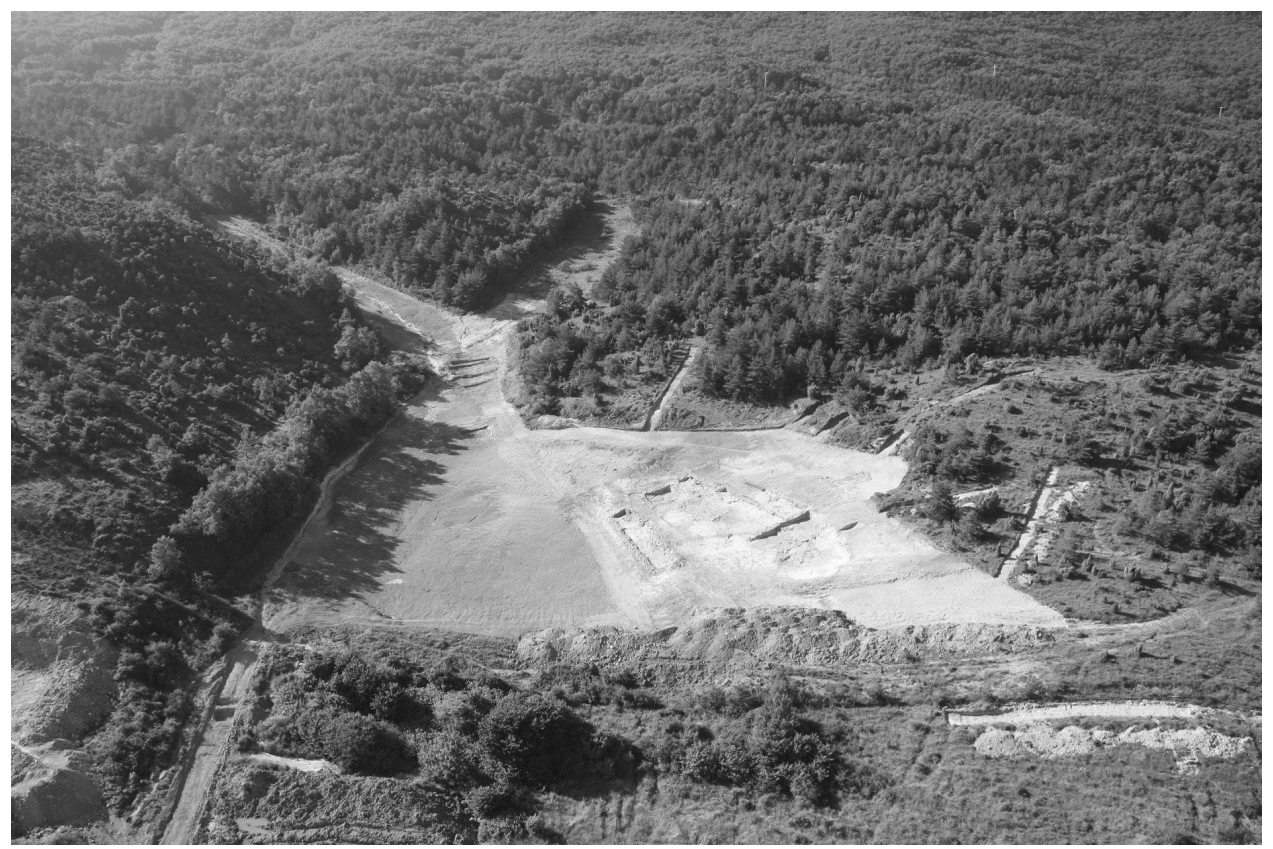


Periodo 1: Siglos V-VII. Se puede atribuir a este momento la realización de algunas granjas a lo largo del valle, de dimensiones limitadas caracterizadas por la presencia de algunas estructuras negativas (silos, algún agujero de poste y zanjas). Son estructuras que han quedado muy alteradas por las fases posteriores, pero que en cualquier caso permiten pensar en la existencia de ocupaciones unifamiliares estables dedicadas a la agricultura.

Periodo 2: Siglos VIII-X. Corresponde a este momento la densificación del asentamiento y la formación de una verdadera comunidad campesina. Se han reconocido una decena de unidades familiares que ocupan tanto la plataforma superior del yacimiento como el fondo del valle formadas por viviendas realizadas sobre zócalos de piedra o estructuras semiexcavadas, con alzados realizados en materiales perecederos. Son muy abundantes los silos asociados a estas estructuras, destacando la existencia en una de las unidades familiares de grandes silos que probablemente haya que interpretar con la existencia de una jerarquía interna dentro de la aldea.

Periodo 3: Siglos X-XII. A partir de este período contamos con indicadores significativos para comprender aspectos básicos del paisaje aldeano (fig. 9).

Figura 9. Vista General del despoblado de Zaballa (IRUÑa de OCA, Álava), DONDE SE HA LOCALIZADO LA ALDEA ALTOMEDIEVAL (SIGLOS VIII-XI) Y EL MONASTERIO DE ZABALLA

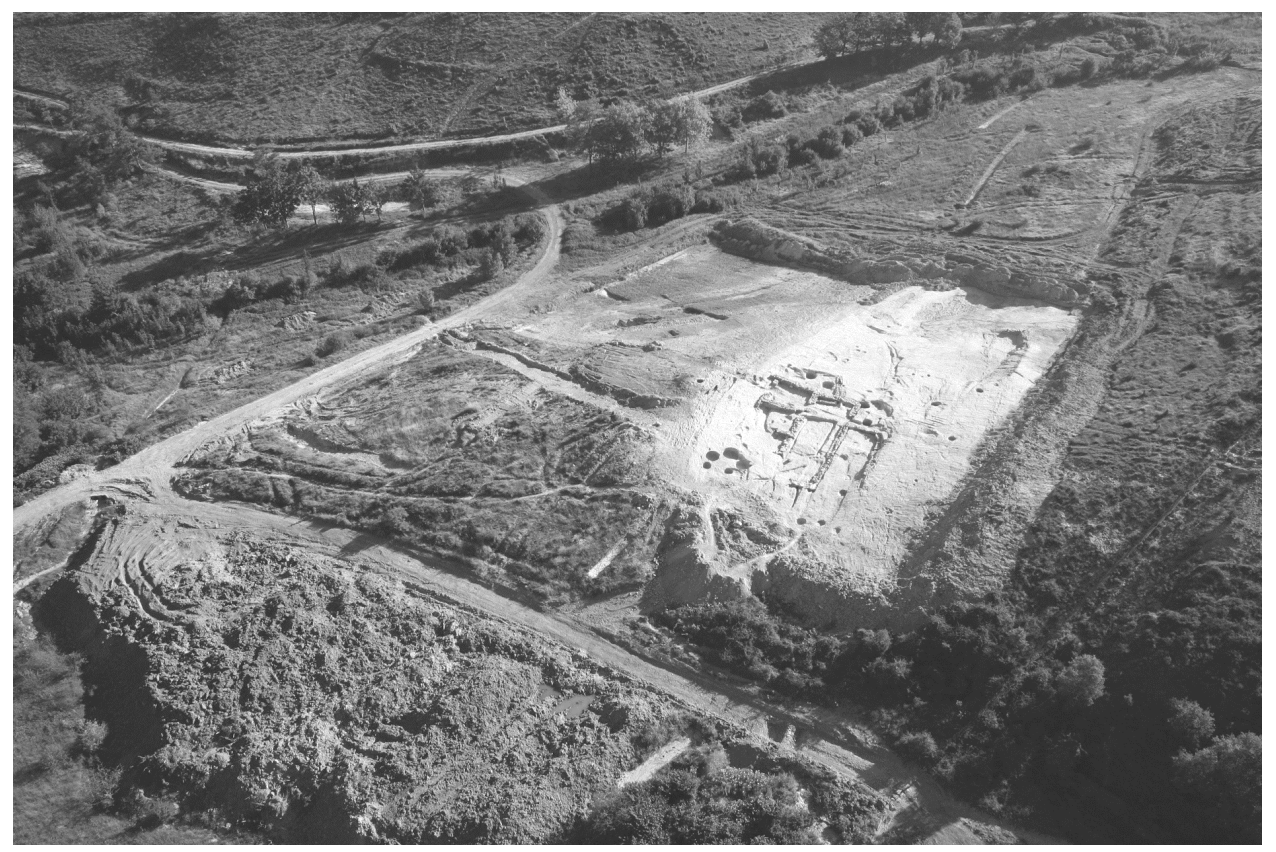


En la plataforma superior de la aldea, donde se encontraban las viviendas dotadas de grandes silos, hacia el $900 \mathrm{ca}$. se funda una iglesia, que probablemente tengamos que identificar con el monasterio de Zaballa recordado en un documento del monasterio de San Millán de la Cogolla del siglo XI.

La construcción de este templo, con varias estructuras anexas y un cementerio, comportó el desplazamiento de la aldea campesina al fondo del valle, que había estado ocupado ya en el período anterior aunque únicamente en su tramo septentrional. La disposición de las viviendas campesinas en el fondo del valle comportó que se regulase la circulación de los cursos de agua que circulaban por el mismo y que se artificializase sus laderas.

Pueden ser fechadas en este momento un conjunto de tres series principales de terrazas situadas en la ladera occidental del valle ${ }^{44}$. Tienen unos 15 metros de anchura y una longitud máxima de unos 60 metros, cubriendo un espacio aterrazado de aproximadamente $4000 \mathrm{~m}^{2}$. Para la construcción de estas terrazas se produjo el desmantelamiento del horizonte vegetal y se colocaron profundos rellenos artificiales de forma sistemática que en ocasiones (sectores 5200, 5300, 5400), superaban el metro de espesor. Sobre este relleno se ha localizado un potente horizonte A resultado de las prácticas agrarias desarrolladas en época medieval. Los bancales estaban rematados en taludes de $45^{\circ}$ y nunca se han localizado muros o estructuras que sustentasen las pendientes. La técnica empleada para la realización de estas terrazas es la denominada por P. Ballesteros como desmonte de ladera con relleno sistemático. Este proceso consistiría en el desmonte hasta el horizonte mineral, aportando a continuación los depósitos de tierra necesarios para construir la terraza (fig. 10).

Período 4: siglos XII-XIV. Corresponde a la última transformación significativa de los paisajes aldeanos de Zaballa y, de hecho, son los más legibles. Hacia finales del siglo XII se produjo una profunda transformación en la estructura de la aldea.

Por un lado, todo el fondo de valle, donde se ubicaban las viviendas de los campesinos, fue rellenado por un potente depósito agrícola que supera con frecuencia el metro de espesor, quedando delimitado al norte por un potente muro de cierre. Se ha calculado que han sido dispuestos casi $10000 \mathrm{~m}^{3}$ de tierra para amortizar todas las estructuras domésticas previas.

A su vez, se ejecutó un sistema hidráulico mediante la realización de una acequia que discurría en el tramo más elevado del fondo del valle (el occidental), y que se abastecía de una red de canales procedentes de las laderas y los manantiales situados en la zona superior del yacimiento. De esta manera se mantiene el cauce elevado respecto al valle y a una serie de parcelas irrigadas utilizadas como huertas, que aparecen delimitadas por un muro principal de trazado quebrado según se disponen las distintas parcelas. Este muro se ha

44 Datación de la unidad estratigráfica 5450 (DSH 1051), $1001 \pm 51$ BP, 899-919 (3\%), 950-958 (1\%), 961-1161 (96\%) cal AD. 
construido exactamente en la caída de la pendiente que marca el afloramiento de la roca base, con el fin de mantener la cota por la que discurre el agua y poder irrigar las parcelas situadas por debajo de este paramento. El muro, que ha sido aparejado sin argamasa, podría interpretarse como el límite de la terraza superior que sujetaba los rellenos realizados para crear suelos arables y regularmente irrigados. De forma perpendicular a este muro principal se han localizado otros menores situados a distancias regulares (6-7 m cada uno) que quizás deban atribuirse a diferencias en propiedades o en usos agrarios. Se configuraría de esta manera un espacio útil formado por una decena de parcelas de unos $60-70 \mathrm{~m}^{2}$. Se trataría por lo tanto de un sistema hidráulico de vertiente de pequeñas dimensiones, con la captación en el fondo de valle, que constituye uno de los modelos más frecuentes atestados en época medieval en otros sectores peninsulares ${ }^{45}$.

\section{FIGURA 10. VISTA DE LA SECCIÓN DE UNA DE LAS TERRAZAS AGRARIAS DEL DESPOBLAdo DE Zaballa (IRUÑA DE OCA, Álava)}

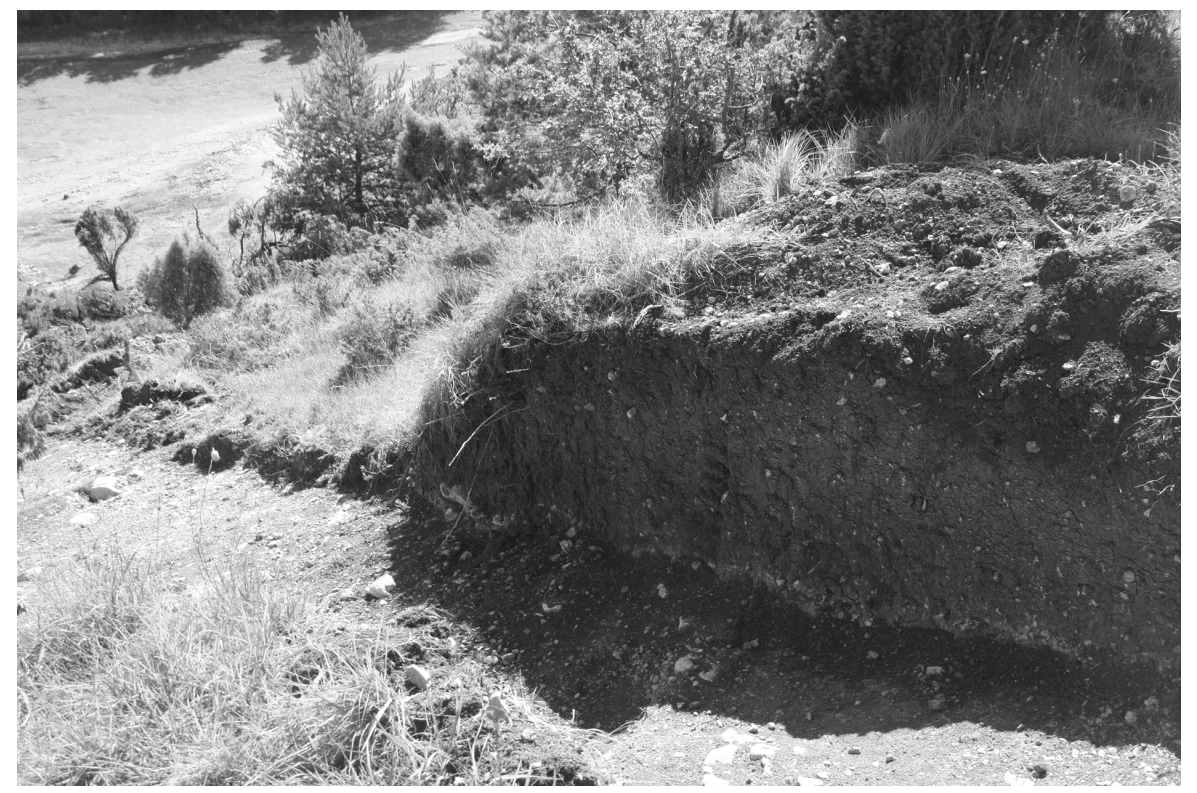

La acequia principal, tras abastecer estas parcelas, circulaba a los pies de un nuevo barrio residencial construido en la ladera occidental, donde previamente se habían realizado varias terrazas agrarias. Es posible que parte de ellas se

45 Sitjes, E., «Inventario y tipología de sistemas hidráulicos en Al-Andalus», Arqueología Espacial, 26 (2006), págs. 280-284. 
desmontasen para acoger este nuevo barrio en el que se agruparon todos los habitantes de la aldea de Zaballa.

Estas viviendas han sido realizadas siguiendo una planificación muy rígida, por lo que pensamos que responden a una acción señorial. El barrio, que ocupa unos $1150 \mathrm{~m}^{2}$ y en el que se han identificado una decena de viviendas, ha sido construido en torno a un patio central. Las casas comparten muros, una red de alcantarillado y servicios comunes, por lo que pensamos que el conjunto ha sido realizado en un período breve de tiempo. Y aunque se han producido numerosas modificaciones de pequeña entidad, la cohesión colectiva de la comunidad sometida al dominio señorial se mantiene. A los pies de este barrio llegaba la acequia principal que alimentaba la decena de huertos irrigados antes señalados.

Mientras, la plataforma superior donde se ubicaba la iglesia se mantuvo como un espacio de referencia de la memoria colectiva de la comunidad, a través del cementerio, y del poder a escala local.

Periodo 5: Siglos XIV-XV. Se corresponde con el abandono paulatino del asentamiento y pérdida de su identidad. Se detectan entonces usos residuales de la necrópolis y algunos saqueos en estructuras que, posiblemente, estuviesen a la vista en estado ruinoso. En los siglos XV y XVI surge un conflicto entre varias instituciones por la gestión de las tierras del despoblado de Zaballa, en particular por la explotación de sus recursos ganaderos.

Este ejemplo es paradigmático de cómo historiar el paisaje agrario desde la óptica de la realidad aldeana, buscando sujetos y encuadrando social y diacrónicamente las modificaciones de los espacios más próximos a los lugares de residencia. Aquí, donde la acción antrópica es más intensa, es posible comprender que aquéllas cerámicas carentes de depósitos arqueológicos coherentes que se habían detectado en un principio, no eran sino el testimonio de los procesos de abonado realizado con residuos domésticos en los campos de cultivo más próximos a las viviendas en los siglos XIII y XIV.

En la construcción de los espacios agrarios de Zaballa, tanto aterrazados como en el fondo de valle, llama la atención el enorme volumen de tierra desplazada. Para la construcción de las terrazas del período 3 ha sido preciso excavar la ladera para buscar la base y desplazar casi unos $1000 \mathrm{~m}^{3}$ de tierra para realizar los espacios aterrazados. Fue, en cambio, mucho más oneroso el relleno sistemático del fondo de valle en el período 4 y la construcción de las parcelas irrigadas. Como se ha señalado, ha sido necesario desplazar casi $10000 \mathrm{~m}^{3}$ de tierra para amortizar todas las viviendas anteriores y construir el nuevo espacio de cultivo intensivo.

Algunos autores que han realizado cálculos teóricos basándose en analogías etnográficas, han calculado que un excavador podría extraer $1 \mathrm{~m}^{3}(=1,5 \mathrm{Tn}$ de tierra poco compacta) en unas 2,7 horas, y una media de 5 Tn al día (equivalente a casi $\left.3,5 \mathrm{~m}^{3}\right)^{46}$. Si consideramos adecuados estos cálculos, para extraer la

46 MAN, J., L'esercito di terracotta. Il primo imperatore cinese e la nascita di una nazione, Milano, Mondadori, 2009, págs. 104-105. 
tierra necesaria para la realización de las terrazas del período 3 habrían sido necesarias unas 285 jornadas de excavación, que en una comunidad de 10-12 aldeanos tendría un coste de tiempo no indiferente. En cambio, para realizar los rellenos del período 4 habrían sido necesarias 2850 jornadas de excavación ${ }^{47}$.

A ello habría que sumar, además, las personas empleadas en el desplazamiento de la tierra en una distancia relativamente breve; podrían ser 2-3 personas por cada excavador. Teniendo en cuenta que la tierra viene del desmonte de las laderas, el desplazamiento habría sido igualmente más complejo de realizar.

Todos estos cálculos, teóricos y aproximativos, dan a entender que la construcción del paisaje aldeano no puede considerarse como una iniciativa espontánea y descoordinada de grupos familiares aislados. La existencia de liderazgos aldeanos o de formas de dominio externos son necesarios para explicar estos procesos, tanto en términos de planificación como de liderazgo y hegemonía a la hora de ejecutar una obra de estas características.

\subsection{Los sectores de almacenaje y de tratamiento}

El estudio integral de los paisajes aldeanos permite comprender aspectos básicos de las prácticas agrarias medievales que no se realizan únicamente en los campos de cultivo. En este caso se hará una breve referencia únicamente a dos aspectos que merecen la pena ser señalados en el estudio del urbanismo aldeano: los espacios vacíos y los sistemas de almacenaje.

Uno de los primeros aspectos que llama la atención a quien se enfrenta a la excavación de un espacio aldeano es la existencia de frecuentes vacíos en los que no se detecta la existencia de estructuras, construcciones o elementos antrópicos de ninguna naturaleza. Es cierto que, como ya se ha señalado, las prácticas agrarias recientes han condicionado la conservación de las estructuras de los pueblos y las aldeas, de tal manera que salvo en el caso de las estructuras negativas, difícilmente localizamos otro tipo de evidencias. Pero hay que comprender que, hoy como ayer, una aldea no es una sucesión de viviendas compactas, sino que hay muchas áreas vacías que han de ser interpretadas e integradas en la comprensión de los espacios aldeanos. Otra consecuencia que se deduce de esto es que, para localizar una aldea, hay que excavar una extensión que no sea nunca inferior a los $300-600 \mathrm{~m}^{2}$ continuos, ya que la posibilidad de encontrar espacios sin estructuras es muy alta.

¿A qué corresponden estos espacios vacíos? En nuestra experiencia pensamos que se corresponden a dos tipos de usos principales: por un lado huertos y espacios de cultivo intensivo situados en proximidad de las viviendas, y con

47 Aplicando esta misma estimación para el caso de las terrazas de Zornoztegi, el desplazamiento de $1600-1800 \mathrm{~m}^{3}$ habría comportado de 450 a 500 jornadas. En el caso de Aistra el desplazamiento de unos $2500 \mathrm{~m}^{3}$ habría comportado unas 700 jornadas de trabajo. 
frecuencia en los límites de las unidades domésticas, y por otro, eras y zonas de trillado, como lo demuestra el hallazgo de piezas de sílex empleados para este tipo de procesos ${ }^{48}$. Estos hallazgos, ya presentes en rellenos de amortización formados en los siglos VIII-IX en yacimientos como Zornoztegi, nos dan una indicación muy relevante sobre el papel que la actividad cerealícola (así como la presencia de ganado) desempeñaba en este proceso.

El segundo elemento al que tenemos que hacer brevemente referencia a la hora de comprender los espacios agrarios medievales en el País Vasco es el estudio de los silos. Los silos excavados en la roca o en los depósitos naturales, constituyen quizás el indicador más precioso que tenemos para localizar las aldeas medievales, aunque solo sea por su visibilidad. Sabemos, que en períodos más recientes los simples agujeros excavados en la roca han sido sustituidos por grandes contenedores cerámicos igualmente enterrados y situados en la plaza y en la proximidad de la iglesia, como ha sucedido en lugares como Cucho (Condado de Treviño, Burgos).

El valor de los silos es doble; por un lado nos proporciona una fotografía precisa sobre el tipo de residuos que genera una aldea en un momento determinado, ya que de su relleno de amortización se obtiene un cuadro coherente de las actividades domésticas y productivas que se realizan cotidianamente. Pero por otro lado el estudio de los silos nos proporciona información muy relevante sobre el proceso de almacenaje y tratamiento de los cereales que se realizaba en estas aldeas ${ }^{49}$.

Sin poder ahondar demasiado sobre la cuestión en esta ocasión, se prestará atención únicamente a las dimensiones de los silos hallados en las aldeas medievales del País Vasco ${ }^{50}$.

En general pensamos que la mayor parte de los silos altomedievales han funcionado como formas de almacenaje a largo plazo por parte de las comunidades campesinas. Aunque creemos que cada unidad doméstica contaba con un único silo, se han hallado casos que permiten pensar que alguna vivienda de Zornoztegi podía tener hasta dos silos en uso contemporáneamente. Este sería, indudablemente, un factor socialmente diferencial en el seno de las comunidades aldeanas.

Las dimensiones de estos silos familiares, que documentamos entre los siglos VIII-X, se mueven entre los 20 y los 30 hectólitros de capacidad. Hay que recordar que los testimonios escritos medievales indican que aproximadamente

48 Ver por ejemplo Benito Del Rey, L., Benito Álvarez, J.M., «La taille actuelle de la pierre a la manière préhistorique. L'exemple des pierres pour Tribula à Cantalejo (Segovia-Espagne)», Bulletin de la Société Prébistorique Française, 91, 3 (1994), págs. 214-222.

49 A escala global, SiguAT, F., Les réserves de grains a long terme: techniques de conservation et fonctions sociales dans l'histoire, Lille, Universite de Lille, 1978.

50 Un estudio sobre la distribución de estos silos en Álava y el uso social que se ha hecho de ellos en Quirós CASTILLO, J.A., «La génesis del paisaje medieval en Álava: la formación de la red aldeana», Arqueología y Territorio Medieval, 13, 1 (2006), págs. 49-94. 
son necesarios unos $32 \mathrm{Hls}$ de cereal para alimentar una familia de 8-10 componentes. Estaríamos hablando, por lo tanto, de una reserva de carácter familiar válida para un año $0^{51}$.

Por otro lado hay que señalar que los silos hallados en las iglesias altomedievales del País Vasco tienen dimensiones similares a los que encontramos en las aldeas de este momento, por lo que se ha excluido que tengan una función directamente relacionada con la obtención masiva de rentas ${ }^{52}$.

No obstante, a partir del año mil y en contextos señoriales, las diferencias se hacen muy notables. En lugares como el castillo de Treviño encontramos silos con capacidades de almacenaje para 40 o 60 hectólitros, y pensamos que dos de ellos estarían en uso a la vez. En este caso nos encontramos lógicamente ante un sistema de almacenaje masivo de rentas de cereales, ligado indudablemente a una práctica especulativa en los años de malas cosechas por parte de los feudales (tabla 2).

TABla 2. Dimensiones DE lOS SILOS DE RENTA DE TREVIÑO

\begin{tabular}{cccccc}
\hline UE & Altura & Diám. & diám. & Hectólitros & Cronol \\
\hline 3110 & 1,24 & 1,89 & 1,59 & 39,3 & s. XII \\
3121 & 1,07 & 1,5 & 1,24 & 21,1 & s. X \\
3130 & 2,21 & 1,91 & 1,22 & 59,0 & s. XII \\
3224 & 1,31 & 1,89 & 0,56 & 26,5 & s. X \\
\hline
\end{tabular}

\subsection{Las especies cultivadas}

Una nueva línea de trabajo que se ha empezado a desarrollar en los últimos años ha sido el estudio de las especies cultivadas a partir del análisis de las semillas halladas en los distintos depósitos arqueológicos.

Los análisis bioarqueológicos con los que contamos en Álava aún no son cuantitativamente muy significativos, por lo que tenemos que movernos con mucha prudencia. De momento solamente se ha publicado un pequeño avance sobre los cultivos documentados en la aldea de Gasteiz en los siglos VIII-X, en el que predomina el trigo común, la cebada vestida, leguminosas, frutos y el lino. Hay que señalar además, la importancia que han tenido cereales de primavera como el panizo, que ayudan a las comunidades campesinas en momen-

51 Fernández Ugalde, A., El fenómeno del relleno de silos y la implantación del feudalismo en Madrid y en el reino de Toledo, IV Congreso de Arqueología Medieval Española, Alicante, 1993, vol. 3, págs. 611-617, pág. 615, n. 4.

52 Quirós Castillo, J.A., «Las iglesias altomedievales en el País Vasco. Del monumento al paisaje», Archivo Español de Arqueología, en prensa. 
tos de necesidad. Asimismo permite diferenciar la existencia de una producción orientada al pago de rentas respecto a otra producción de autoconsumo que no aparece en los testimonios escritos ${ }^{53}$.

Los análisis que se están realizando en Zornoztegi (fig. 11) y en otras aldeas similares arrojan resultados muy parejos, aunque se encuentran en una fase de elaboración inicial ${ }^{54}$.

Figura 11. ANÁlisis DEL RELlENO DE UN SILO DEL SIGLO X DE LA ALDEA DE ZORNOZTEGI ${ }^{55}$ (AgURAIN, ÁlaVA)

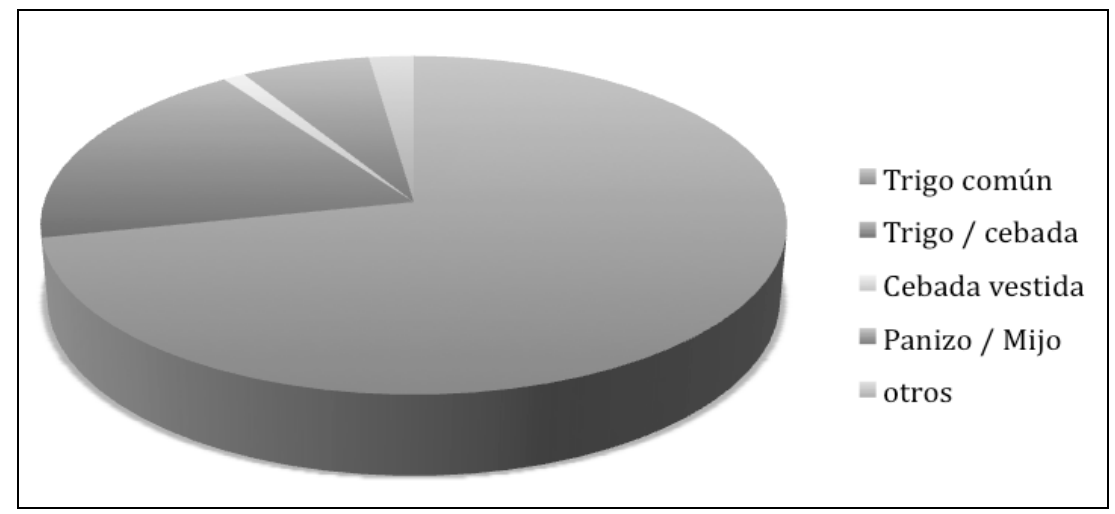

En todo caso, hay que señalar que a partir de los primeros análisis arqueofaunísticos que se están realizando, lo que resulta muy evidente es la existencia, al menos desde el siglo VIII, de una fuerte e intensa integración entre la ganadería y la agricultura para desarrollar un modelo productivo complejo. Predominan sustancialmente los bóvidos, que presentan edades de sacrificio muy avanzadas, así como los ovicápridos, que se explotaban para leche, carne y otros derivados. Es más escasa, en cambio, la presencia del cerdo, que raramente alcanza edades óptimas para la producción de carne ${ }^{56}$.

53 AzKarate, A., Zapata, L., «Agricultura altomedieval en Vitoria-Gasteiz: La aportación de la arqueobotánica», en: Jornades sobre Sistemes Agraris, Organització social i poder als Paisos Catalans, Lleida, págs. 701-710.

54 Itxaso Sopelana está realizando en la actualidad una tesis doctoral sobre esta temática en el Departamento de Geografía, Prehistoria y Arqueología de la Universidad del País Vasco. SopelanA, I., Zapata, L., "Primeros resultados de los estudios carpológicos del despoblado de Zornoztegi (Salvatierra-Agurain, Álava)», en: QuiRós CASTILLO, J.A, The archaeology of early medieval village in Europe, Bilbao, págs. 439-447.

55 Unidad estratigráfica 1606 (DSH 350), $1115 \pm 29$ BP, 871-997 (99\%) cal AD.

56 Idoia Grau está realizando en la actualidad una tesis doctoral sobre esta temática en el Departamento de Geografía, Prehistoria y Arqueología de la Universidad del Pais Vasco. 


\section{Algunas CONClusiones}

De todo lo dicho hasta el momento, y teniendo en cuenta que no resulta sencillo evaluar la representatividad de los ejemplos de los que disponemos hasta el momento, podemos formular una serie de conclusiones para el territorio alavés en el período comprendido entre los siglos V-XIII:

- En primer lugar, los tenues indicios arqueológicos que estamos empezando a detectar en los últimos años sobre la Arqueología del campesinado en el período comprendido entre el 450-700 no permiten aún trazar un cuadro muy preciso sobre las formas de ocupación y explotación del territorio ${ }^{57}$. En todo caso, ideas como la inestabilidad, la dispersión del poblamiento, el predominio de la ganadería o la regresión económica no parecen ajustarse a los indicadores que tenemos. Los habitantes de las cuevas de Los Husos practicaban una agricultura intensiva, lo mismo que los habitantes de la granja de La Erilla (donde se han hallado varios silos para el almacenaje del cereal) ${ }^{58}$. Pero son sin ninguna duda las terrazas agrarias de Aistra fechadas entre los siglos V-VI las que permiten pensar en la existencia de una actividad agraria intensiva desde los primeros momentos de la fundación de la aldea medieval. Es cierto que aún tenemos que analizar con mayor detalle las aldeas de Zornoztegi o Aistra en este período, pero es bastante probable que las diferencias no sean muy marcadas, al menos en términos cualitativos, respecto a los modelos productivos documentados con posterioridad.

- En segundo lugar hay que señalar que hacia el siglo VIII se documenta la existencia de un cambio relevante en el paisaje rural alavés, que no podemos aún caracterizar en términos de «crecimiento». De hecho no se observa la existencia de un proceso gradual de "crecimiento», sino que los indicadores con lo que contamos muestran ya desde el primer momento una estructura productiva muy articulada y compleja, basada en la llanada alavesa en la integración entre una agricultura y una ganadería intensiva. Aún no se conocen estructuras agrarias que podamos atribuir a este período con claridad en nuestro territorio, pero no se observan variaciones significativas por ejemplo en la capacidad de almacenaje de los silos durante los siglos VIII-X o cambios cualitativos en las prácticas agrarias ${ }^{59}$. En otros

57 Quirós CAStillo, J.A, «Las aldeas altomedievales...».

58 Sobre La Erilla ver Quirós Castillo, J.A, Vigil EsCALERA, A., «Networks of peasant villages between Toledo and Uelegia Alabense, Northwestern Spain $\left(\mathrm{V}^{\text {th }}-\mathrm{X}^{\text {th }}\right.$ centuries)», Archeologia Medievale, XXXIII (2007), págs. 79-128; sobre las ocupaciones rupestres Quirós CASTILLO, J.A, Alonso, A., «Las ocupaciones rupestres en el fin de la Antigüedad. Los materiales cerámicos de Los Husos (Elvillar, Álava)», Veleia, 24-25 (2008), págs. 1123-1142.

59 Este tipo de modelo económico mixto y con este tipo de orientaciones presenta paralelos en muchas otras aldeas coetáneas europeas. Una de las mejor estudiadas es la de Saleux, en Somme 
contextos del norte de Europa sí se ha podido verificar arqueológicamente una intensificación de la producción a partir de los siglos VIII-IX, que con frecuencia se ha traducido en nuevas prácticas agrarias, como la introducción de la rotación o en el incremento de algunas producciones como el centeno, aunque las variaciones regionales son muy notables ${ }^{60}$.

- La producción campesina altomedieval alavesa produce excedentes que satisfacen no solamente las necesidades inmediatas de la comunidad, sino que permiten además un almacenaje de emergencia para años difíciles y el pago de rentas. Parece además que existe un equilibrio entre la producción de cereales de primavera, orientados hacia el autoconsumo, y los cereales de invierno utilizados para el pago de las rentas. Hasta el momento en nuestros yacimientos no se han observado los efectos que podría haber tenido la potenciación que realizan las élites sociales alavesas de la ganadería extensiva que se puede observar a partir de la documentación escrita ${ }^{61}$. Esto podría deberse, entre otros motivos, a que esta tendencia está más documentada en el occidente alavés que en la propia llanada, que probablemente en este período ya se encuentra densamente ocupada por redes de aldeas dedicadas a la producción cerealícola.

- A partir del año mil la escenificación del poder aristocrático se hace más visible, bien a través de la fundación de redes de castillos bien con la multiplicación de las iglesias y los monasterios propios. En términos cuantitativos si que creemos que podemos hablar en este momento de un crecimiento de la capacidad de captación de rentas por parte de los señores. Los silos hallados en Treviño o el aumento de las zonas de cultivo intensivo en Zornoztegi podrían ser indicadores de este tipo de procesos. Aún no estamos en condiciones, en cambio, de determinar si este crecimiento cuantitativo supone un cambio cualitativo en las prácticas y los usos agrarios. Esta es una tendencia que se observa en otros contextos europeos en los que si bien durante la Alta Edad Media el poder se basa en la extracción creciente de rentas ${ }^{62}$, a partir de un determinado momento los señores ordenan a una esfera más compleja la producción campesina, imponiendo estrategias y orientaciones productivas ${ }^{63}$.

- A partir del XII-XIII se produce un nuevo giro de tuerca en un contexto fuertemente señorializado y de alta competencia entre poderes locales y subregionales. El ejemplo de Zaballa representa, en términos de planificación señorial de la producción, un caso muy significativo. La modifica-

(PERrin, P., «The origin of the village in Early Medieval Gaul», en: Christie, N., Landscape of change, Leicester, 2004, págs. 262-265).

60 HAMEROW, Early medieval settlements..., págs. 140 y ss.

61 GARCÍA DE CORTAZAR, «La sociedad alavesa medieval...».

62 HaMEROW, Early medieval settlements..., págs. 4 y 140.

63 BARCELÓ, "Crear, disciplinar y dirigir el desorden...». 
ción del paisaje agrario y del paisaje habitado es muy profunda, y no queda ningún margen para la improvisación ni para la «espontaneidad» del campesinado.

\section{AgRAdeCIMIENTOS}

Lorena Elorza leyó una versión inicial de este texto. Este trabajo debe mucho a todos mis colaboradores y compañeros con los que trabajamos en varios proyectos, especialmente M. Fernández, A. Reynolds y P. Ballesteros y todos los miembros del Grupo de Investigación en Arqueología Medieval y Postmedieval de la Universidad del País Vasco. Agradezco igualmente a dos evaluadores externos sus comentarios, que han mejorado el texto.

Recibido: 17-03-2009

Aceptado: 09-12-2009 